\title{
New-generation stents compared with coronary bypass surgery for unprotected left main disease: A word of caution
}

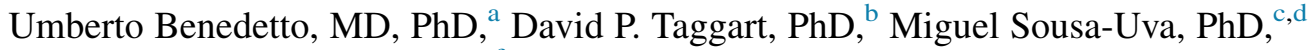 \\ Giuseppe Biondi-Zoccai, MD, ${ }^{\mathrm{e}, \mathrm{f}}$ Antonino Di Franco, MD, ${ }^{\mathrm{g}}$ Lucas B. Ohmes, MD, ${ }^{\mathrm{g}}$ \\ Mohamed Rahouma, MD, ${ }^{\mathrm{g}}$ Mohamed Kamel, MD, ${ }^{\mathrm{g}}$ Massimo Caputo, MD, ${ }^{\mathrm{a}}$ Leonard N. Girardi, MD, ${ }^{\mathrm{g}}$ \\ Gianni D. Angelini, MD, and Mario Gaudino, MD $^{\mathrm{g}}$
}

\section{ABSTRACT}

Background: With the advent of bare metal stents and drug-eluting stents, percutaneous coronary intervention has emerged as an alternative to coronary artery bypass grafting surgery for unprotected left main disease. However, whether the evolution of stents technology has translated into better results after percutaneous coronary intervention remains unclear. We aimed to compare coronary artery bypass grafting with stents of different generations for left main disease by performing a Bayesian network meta-analysis of available randomized controlled trials.

Methods: All randomized controlled trials with at least 1 arm randomized to percutaneous coronary intervention with stents or coronary artery bypass grafting for left main disease were included. Bare metal stents and drug-eluting stents of first- and second-generation were compared with coronary artery bypass grafting. Poisson methods and Bayesian framework were used to compute the head-to-head incidence rate ratio and $95 \%$ credible intervals. Primary end points were the composite of death/myocardial infarction/stroke and repeat revascularization.

Results: Nine randomized controlled trials were included in the final analysis. Six trials compared percutaneous coronary intervention with coronary artery bypass grafting $(\mathrm{n}=4654)$, and 3 trials compared different types of stents $(\mathrm{n}=1360)$. Follow-up ranged from 6 months to 5 years. Second-generation drug-eluting stents (incidence rate ratio, 1.3; 95\% credible interval, 1.1-1.6), but not bare metal stents (incidence rate ratio, $0.63 ; 95 \%$ credible interval, $0.27-1.4$ ), and firstgeneration drug-eluting stents (incidence rate ratio, $0.85 ; 95 \%$ credible interval, 0.65-1.1) were associated with a significantly increased risk of death/myocardial infarction/stroke when compared with coronary artery bypass grafting. When compared with coronary artery bypass grafting, the highest risk of repeat revascularization was observed for bare metal stents (hazard ratio, 5.1; 95\% confidence interval, 2.1-14), whereas first-generation drug-eluting stents (incidence rate ratio, $1.8 ; 95 \%$ confidence interval, 1.4-2.4) and second-generation drug-eluting stents (incidence rate ratio, $1.8 ; 95 \%$ confidence interval, 1.4-2.4) were comparable.

Conclusions: The introduction of new-generation drug-eluting stents did not translate into better outcomes for percutaneous coronary intervention when compared with coronary artery bypass grafting. (J Thorac Cardiovasc Surg 2018;155:2013-19)

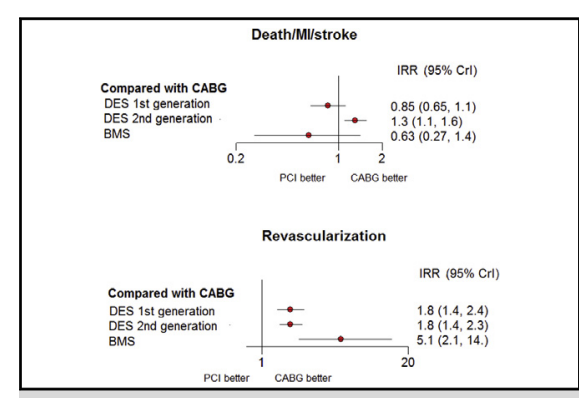

The IRR for death/MI/stroke and reintervention with BMS and first- and second-generation DESs using CABG as a comparator.

\section{Central Message}

The introduction of new-generation DESs for unprotected LMD did not translate into better clinical outcomes compared with CABG.

\section{Perspective}

Whether the evolution of stent technology has translated into better results after PCI for unprotected LMD remains unclear. The present NMA suggests that new-generation stents are not associated with better outcomes when compared with $\mathrm{CABG}$.

See Editorial Commentary page 2020.

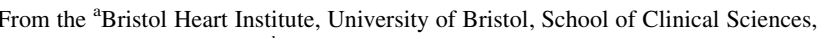
Bristol, United Kingdom; ' Nuffield Department of Surgical Sciences, University of Oxford, Oxford, United Kingdom; 'Cardiac Surgery Department, Hospital Cruz Vermelha, Lisbon, Portugal; ${ }^{\mathrm{d} D e p a r t m e n t ~ o f ~ S u r g e r y ~ a n d ~ P h y s i o l o g y ~ C a r d i o v a s c u-~}$ lar Research Centre, Faculdade de Medicina Universidade do Porto, Porto, Portugal; ${ }^{\mathrm{e}}$ Department of Medico-Surgical Sciences and Biotechnologies, Sapienza University of Rome, Rome, Italy; ${ }^{\mathrm{f}}$ Department of AngioCardioNeurology, IRCCS Neuromed, Pozzilli, Italy; and ${ }^{\mathrm{g}}$ Department of Cardiothoracic Surgery, Weill Cornell Medicine, New York, NY.
}

Supported by The National Institute for Health Research Bristol Biomedical Research Centre (NIHR Bristol BRC).

Received for publication March 24, 2017; revisions received Oct 31, 2017; accepted for publication Nov 17, 2017; available ahead of print Jan 12, 2018.

Address for reprints: Umberto Benedetto, MD, PhD, Bristol Heart Institute, University of Bristol, Upper Maudlin St, Bristol BS2 8HW, United Kingdom (E-mail: umberto.benedetto@bristol.ac.uk).

$0022-5223 / \$ 36.00$

Copyright (c) 2017 by The American Association for Thoracic Surgery

https://doi.org/10.1016/j.jtcvs.2017.11.066 


$$
\begin{aligned}
& \text { Abbreviations and Acronyms } \\
& \text { Bio-ES }=\text { Biolimus-eluting stent } \\
& \text { BMS }=\text { bare metal stent } \\
& \text { CABG }=\text { coronary artery bypass grafting } \\
& \text { CrI }=\text { credible interval } \\
& \text { DES }=\text { drug-eluting stent } \\
& \text { EES }=\text { everolimus-eluting stent } \\
& \text { IRR }=\text { incidence rate ratio } \\
& \text { LMD } \\
& \text { MI left main disease } \\
& \text { NMA }=\text { myocardial infarction } \\
& \text { PCI }=\text { percutaneous coronary intervention } \\
& \text { PES }=\text { paclitaxel-eluting stent } \\
& \text { RCT }=\text { randomized controlled trial } \\
& \text { SES }=\text { sirolimus-eluting stent } \\
& \text { ZES }=\text { zotarolimus-eluting stent }
\end{aligned}
$$

(4) $\begin{aligned} & \text { Scanning this QR code will take } \\ & \text { you to supplemental figures and } \\ & \text { tables for this article. }\end{aligned}$

Coronary artery bypass grafting (CABG) has long been considered superior to percutaneous coronary intervention (PCI) in the treatment of choice for unprotected left main disease (LMD). ${ }^{1}$ However, with the advent of bare metal stents (BMSs) and first-generation drug-eluting stents (DESs), including paclitaxel-eluting stents (PESs) and sirolimus-eluting stents (SESs), PCI has emerged as an attractive alternative. ${ }^{1,2}$ The recent introduction of second-generation DES, including everolimus-eluting stents (EESs), zotarolimus-eluting stents (ZESs), and biodegradable polymer Biolimus-eluting stents (Bio-ESs), has further promoted PCI in this setting. ${ }^{3}$

However, whether the evolution of stent technology has translated into better results after PCI remains unclear. Despite the lack of definitive evidence on the equipoise between PCI with second-generation DES and CABG in terms of hard clinical end points, the current trend is to perform PCI rather than CABG when technically feasible. We aimed to compare CABG with stents of different generations for LMD by performing a Bayesian network meta-analysis (NMA) of available randomized controlled trials (RCTs).

\section{MATERIAL AND METHODS}

This work was designed as a systematic review and NMA, with reporting following the Preferred Reporting Items for Systematic Reviews and Meta-Analysis statement. ${ }^{4,5}$

\section{Data Sources and Searches}

We searched PubMed, the Cochrane Central Register of Controlled Trials, and EMBASE from their inception to November 2016, without language restrictions. Search algorithm used was "left main" AND ("percutaneous coronary intervention" OR PCI OR stent*) AND ("coronary artery bypass" OR CABG OR "bypass surgery" OR "coronary bypass"). Reference lists of the identified reports and relevant reviews were manually screened by 3 reviewers (UB, $\mathrm{ADF}, \mathrm{LBO}$ ) to identify further relevant studies. In addition, when other meta-analyses, systematic reviews, or RCTs were found, we used backward snowballing (ie, scanning of references of retrieved articles and pertinent reviews) to obtain further studies.

\section{Study Selection}

Investigators first examined references at the title/abstract level, with divergences resolved by consensus, and then, if potentially pertinent, retrieved the complete articles. Articles were included in the present analysis if they fulfilled the following inclusion criteria: random allocation to treatment, at least 1 group randomized to CABG or PCI with stents for unprotected LMD.

\section{Data Extraction and Quality Assessment}

Baseline including SYNTAX score, ${ }^{6}$ procedural outcome, and followup data were independently abstracted by 2 investigators. In the present analysis, outcomes were adjudicated according to the original authors' definitions. Outcomes were analyzed according to the intention-to-treat principle whenever possible. The internal validity and risk of bias of included trials were appraised by 2 independent investigators (U.B., M.R., M.K.) according to the "risk of bias assessment tool" developed by the Cochrane collaboration. ${ }^{7}$ Briefly, for each trial, 7 domains were assessed: random sequence generation, allocation concealment, blinding of participants and personnel, blinding of outcome assessors, incomplete outcome data reporting, selective reporting, and presence of other bias. The presence of a possible source of bias in each domain was assessed, and a final judgment of low, moderate, or high risk of bias was assigned.

\section{End Points}

The primary end point was the commonly adopted composite of death, myocardial infarction (MI), or stroke (death/MI/stroke) at the longest follow-up available. Because second-generation stents are anticipated to reduce the risk of restenosis, repeat revascularization was also considered a primary end point. Secondary end points were mortality, MI, and stroke.

\section{Data Synthesis and Analysis}

The NMA was conducted using R (version 3.2.0, R Project for Statistical Computing) with the gemtc and rjags packages, which interface with Just Another Gibbs Sampler (JAGS) software (version 3.4.0). Two separate analyses were conducted. The first analysis compared different stent generations with CABG, and stents were categorized into 3 groups: BMS; DES of first generation, which included PES and SES; and DES of second-generation, which included Bio-ES, EES, and ZES. The second analysis compared individual stent types with CABG.

When modeling the clinical outcomes of interest, it is important to consider the different follow-up times of the various trials, because longer follow-up is likely to result in more reported events. To account for this, an underlying Poisson process with a constant event rate was assumed with the total number of events observed within a treatment group out of the total person-time of follow-up for that treatment group calculated from study follow-up. A log link function was used to model the incidence rate. ${ }^{8}$

Relative effect estimates from the NMA were calculated as log incidence rate ratios (IRRs) with $95 \%$ credible intervals (CrIs). For all practical purposes, incidence rates can be thought of as hazards, and thus the IRR can be roughly interpreted as the hazard ratio. Incidence of primary 
end points observed in each treatment arm for each included trial was extracted and pooled using the Bayesian fixed effects model. ${ }^{9}$ A fixed-effects model was chosen because it had a lower deviance information criterion compared with the random effects model, suggesting a better model fit. Noninformative prior distributions were chosen for model parameters so that results were driven entirely by the reported data. Analyses were performed using Markov-Chain Monte-Carlo methods, a method that estimates the effect of each treatment comparison by simulation, using 4 chains with 100,000 iterations and thinning interval of 10, after a burn-in of 50,000. ${ }^{9}$ Convergence of the chains was assessed using the Gelman plot and diagnostic test. ${ }^{10}$ Statistical significance was considered when the CrIs did not cross the line of no effect. The effect of SYNTAX score on treatment effect was investigated using meta-regression analysis as proposed by Gelman and colleagues. ${ }^{11}$

\section{Consistency}

An assumption of NMA models is that direct and indirect sources of evidence estimate the same true treatment effect. This was evaluated by conducting conventional pairwise meta-analyses and testing consistency by comparing the direct and indirect evidence results to see if a statistically significant difference existed. We applied the back-calculation method to check for consistency within the evidence networks. ${ }^{12}$ On the basis of the back-calculation method, the difference between direct and indirect estimate was considered as an estimate of inconsistency. Our null hypothesis was that there was consistency between the direct and indirect evidence, and we would reject the null hypothesis if there was a statistically significant difference between the direct and indirect evidence comparison $(P<.05)$.

For a secondary analysis, a pairwise meta-analysis was conducted to pool data from RCTs comparing PCI with CABG for primary end points, with subgroup analysis according to the type of stents used. We derived the $\log$ IRR and corresponding standard error from numbers of reported events and accumulated person-years of follow-up. Log IRRs were pooled using the generic inverse variance method with random and fixed model. Hypothesis of statistical heterogeneity was tested by means of Cochran Q test, with statistical significance set at the 2-tailed 0.10 level, and extent of statistical consistency was measured with $\mathrm{I}^{2}$, defined as $100 \% \times(\mathrm{Q}-\mathrm{df}) / \mathrm{Q}$, where $\mathrm{Q}$ is Cochran's heterogeneity statistic and the degrees of freedom.

\section{RESULTS}

Of 2597 potentially relevant articles initially screened, 9 met the inclusion criteria and were included in the final analysis. ${ }^{1-3,13-18}$ A flow diagram of study selection is reported in Figure E1. An overview of the study characteristics in individual RCTs is shown in Table 1, Table E1, and Table E2. Internal validity assessment for each trial is reported in Table E3. Overall, 6 studies ${ }^{1-3,13-15}$ compared PCI and CABG $(n=4654)$ and 3 studies $^{16-18}$ compared different types of stents $(n=1360)$. Follow-up ranged from 6 months to 5 years.

For the analysis based on different stent generations, 7 studies $^{1-3,13-16}$ were included. Erglis and colleagues ${ }^{16}$ did not report the stroke rate separately. For the analysis based on different stent generations, all 9 studies identified were included (Figure 1).

\section{Network Meta-analysis}

NMA estimates for primary and secondary end points are reported in Figures 2 and 3 for the analysis based on different stent generations and in Figures 4 and 5 for the analysis based on stents of different type. BMS (IRR, $0.63 ; 95 \%$ CrI, 0.27-1.4) and first-generation DES (IRR, $0.85 ; 95 \%$ CrI, $0.65-1.1$ ) did not significantly differ from CABG for the composite of death/MI/stroke. Secondgeneration DESs were associated with a significantly

TABLE 1. Characteristics of randomized controlled trials included in the network meta-analysis

\begin{tabular}{|c|c|c|c|c|c|c|c|c|c|}
\hline Trial & Year & $\begin{array}{c}\text { Treatment } \\
\text { received }\end{array}$ & $\begin{array}{c}\text { euroSCORE } \\
\text { (PCI) }\end{array}$ & $\begin{array}{c}\text { euroSCORE } \\
\text { (CABG) }\end{array}$ & $\begin{array}{l}\text { SYNTAX } \\
\text { (PCI) }\end{array}$ & $\begin{array}{c}\text { SYNTAX } \\
\text { (CABG) }\end{array}$ & $\begin{array}{l}\text { Not isolated } \\
\text { LMD, \% }\end{array}$ & $\begin{array}{c}\text { Distal } \\
\text { LMD, \% }\end{array}$ & $\begin{array}{c}\text { Follow-up } \\
(y)\end{array}$ \\
\hline NOBLE & 2016 & CABG vs Bio-ES & $2(2,4)$ & $2(2,4)$ & $22.5 \pm 7.5$ & $22.4 \pm 8.0$ & NA & 81 & 3.1 \\
\hline EXCEL & 2016 & CABG vs EES & NA & NA & $26.9 \pm 8.8$ & $26.0 \pm 9.8$ & 82.2 & 79.2 & 3 \\
\hline LE MANS & 2016 & CABG vs BMS & $3.3 \pm 2.3$ & $3.5 \pm 2.3$ & $25.2 \pm 8.7$ & $24.7 \pm 6.8$ & 94 & 60 & 1 \\
\hline PRECOMBAT & 2015 & CABG vs SES & $2.6 \pm 1.8$ & $2.8 \pm 1.9$ & $24.4 \pm 9.4$ & $25.8 \pm 10.5$ & NA & 67 & 5 \\
\hline SYNTAX & 2014 & CABG vs PES & $3.9 \pm 2.8$ & $3.9 \pm 2.9$ & $29.6 \pm 13.5$ & $30.2 \pm 12.7$ & 85.9 & 58.3 & 5 \\
\hline $\begin{array}{l}\text { Boudriot and } \\
\text { colleagues }^{14}\end{array}$ & 2011 & CABG vs SES & $2.4(1.5,3.7)$ & $2.6(1.7,4.9)$ & $24.0(19.0,29.0)$ & $23.0(14.8,28.0)$ & 71 & 69 & 1 \\
\hline $\begin{array}{l}\text { Erglis and } \\
\text { colleagues }^{16}\end{array}$ & 2007 & BMS vs PES & NA & - & $32.6 \pm 11.7$ & - & 49 & 75 & 0.5 \\
\hline $\begin{array}{l}\text { ISAR-LEFT- } \\
\text { MAIN }\end{array}$ & 2009 & PES vs SES & $4.7 \pm 3.4$ & - & NA & - & NA & 64 & 1 \\
\hline $\begin{array}{l}\text { ISAR-LEFT- } \\
\text { MAIN } 2\end{array}$ & 2013 & ZES vs EES & $5.1 \pm 3.7$ & & NA & - & NA & 79 & 1 \\
\hline
\end{tabular}

Values are mean, median (interquartile range), or \%. euroSCORE, European System for Cardiac Operative Risk Evaluation; $P C I$, percutaneous coronary intervention; CABG, coronary artery bypass grafting; SYNTAX, Synergy between Percutaneous Coronary Intervention with Taxus and Cardiac Surgery trial; $L M D$, left main disease; NOBLE, NordicBaltic-British left main revascularisation study; Bio-ES, biolimus-eluting stent; NA, not available; EXCEL, Evaluation of XIENCE versus Coronary Artery Bypass Surgery for Effectiveness of Left Main Revascularization trial; EES, everolimus-eluting stent; LE MANS, Study of Unprotected Left Main Stenting Versus Bypass Surgery; BMS, bare metal stents; PRECOMBAT, Premier of Randomized Comparison of Bypass Surgery versus Angioplasty Using Sirolimus-Eluting Stent in Patients with Left Main Coronary Artery Disease trial; SES, sirolimus-eluting stents; PES, paclitaxel-eluting stents; ISAR-LEFT-MAIN, Intracoronary Stenting and Angiographic Results: Drug-Eluting Stents for Unprotected Coronary Left Main Lesions; ZES, zotarolimus-eluting stent. 

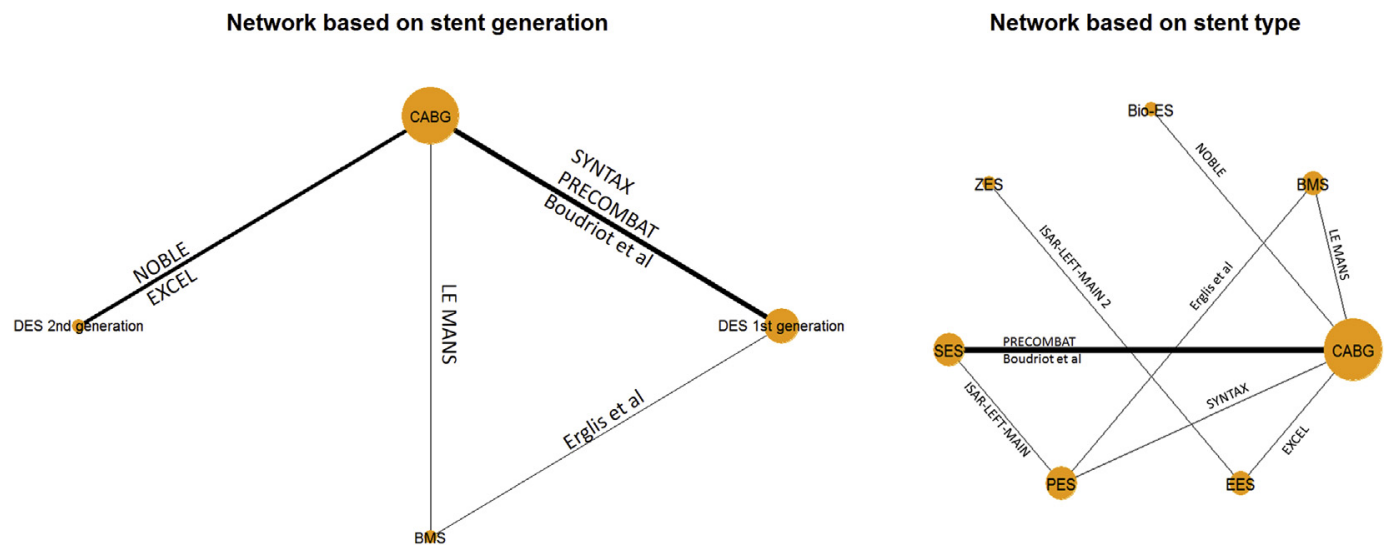

FIGURE 1. Network plots of relevant studies based on stent generation (left) and stent type (right). Circles represent each revascularization strategy as a node, and lines represent the direct comparisons. The extent of circle indicates the number of patients receiving each revascularization strategy, and the line thickness indicates the number of studies included in each comparison. DES first-generation include PES and SES; DES second-generation include Bio-ES, EES, and ZES. DES, Drug-eluting stents; NOBLE, Nordic-Baltic-British left main revascularisation study; EXCEL, Evaluation of XIENCE versus Coronary Artery Bypass Surgery for Effectiveness of Left Main Revascularization trial; $C A B G$, coronary artery bypass grafting; LE MANS, Study of Unprotected Left Main Stenting Versus Bypass Surgery; BMS, bare metal stent; SYNTAX, Synergy between Percutaneous Coronary Intervention with Taxus and Cardiac Surgery trial; PRECOMBAT, Premier of Randomized Comparison of Bypass Surgery versus Angioplasty Using Sirolimus-Eluting Stent in Patients with Left Main Coronary Artery Disease trial; SES, sirolimus-eluting stents; ZES, zotarolimus-eluting stent; Bio-ES, biolimus-eluting stent; EES, everolimus-eluting stent; PES, paclitaxel-eluting stents; ISAR-LEFT-MAIN, Intracoronary Stenting and Angiographic Results: Drug-Eluting Stents for Unprotected Coronary Left Main Lesions.

increased risk of death/MI/stroke when compared with CABG (IRR, 1.3; 95\% CrI, 1.1-1.6). This result was driven by an increased risk of MI with Bio-ES (IRR, 3.0; 95\% CrI, 1.5-6.4), a nonsignificant trend toward an increased risk of

\section{Death/MI/stroke}

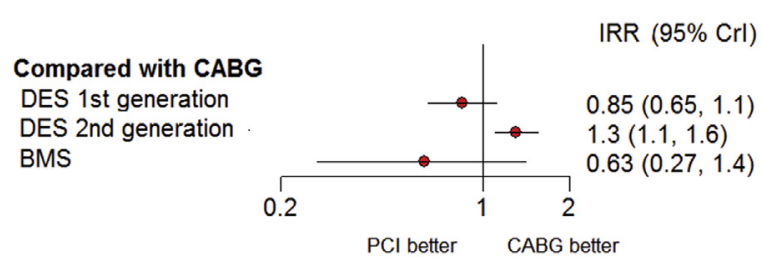

Revascularization

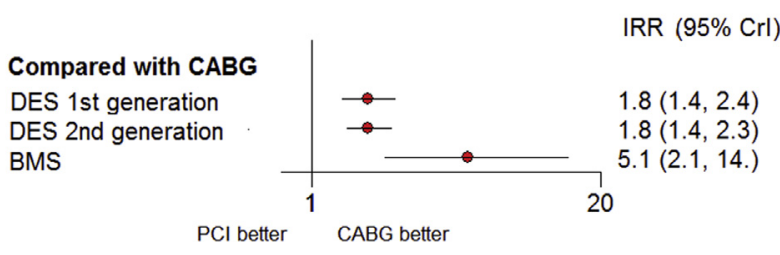

FIGURE 2. NMA estimates for the primary end points at latest follow-up (expressed as IRR, with relative $95 \% \mathrm{CrI}$ ) for different stent generations (DES first-generation include PES and SES; DES second-generation include Bio-ES, EES, and ZES). CABG as comparator. MI, Myocardial infarction; $C A B G$, coronary artery bypass grafting; $D E S$, drug-eluting stents; $B M S$, bare metal stent; $P C I$, percutaneous coronary intervention; $I R R$, incidence rate ratio; $\mathrm{CrI}$, credible interval. death and MI with ZES, and a marginally nonsignificant increased risk of death with EES (IRR, 1.4; 95\% CrI, 0.97-1.9) (Table E4).

When compared with CABG, the highest risk of repeat revascularization was observed for BMSs (hazard ratio, $5.1 ; 95 \%$ CI, 2.1-14), whereas such a risk was comparable between first-generation DES (IRR, 1.8; 95\% CI, 1.4-2.4) and second-generation DES (IRR, 1.8; 95\% CI, 1.4-2.4).

The comparison between CABG and different type of stents was constant across SYNTAX score values for both the composite of death/MI/stroke and repeat revascularization (Figures E2 and E3). No significant inconsistency was found between direct and indirect comparison within network loops for the analysis based on different stent generations (Figures E4 and E5) and different types of stents (Figures E6 and E7).

\section{Pairwise Meta-analysis Percutaneous Coronary Intervention Versus Coronary Artery Bypass Grafting}

Pairwise comparison between PCI and CABG was based on 6 RCTs. Overall, PCI and CABG were comparable for death/MI/stroke (IRR, 0.99; 95\% CI, 0.70-1.4). However, although first-generation DESs were associated with a nonsignificant $11 \%$ relative risk reduction of death/MI/ stroke when compared with $\mathrm{CABG}$, second-generation DESs were associated with a $33 \%$ relative risk increase (Figure E8). Pairwise comparison confirmed that firstgeneration DES (IRR, 1.82; 95\% CI, 1.39-2.4) and 
Mortality

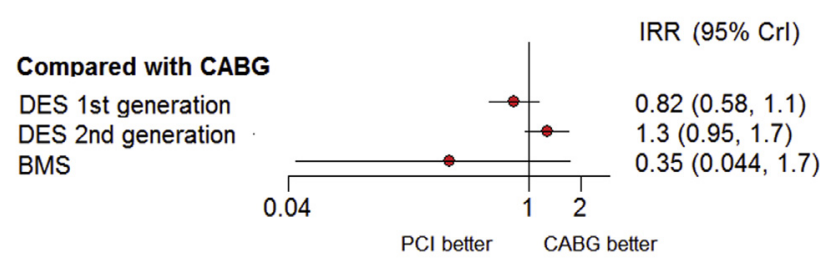

MI

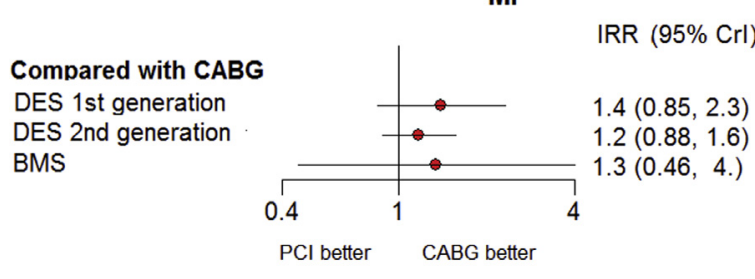

Stroke

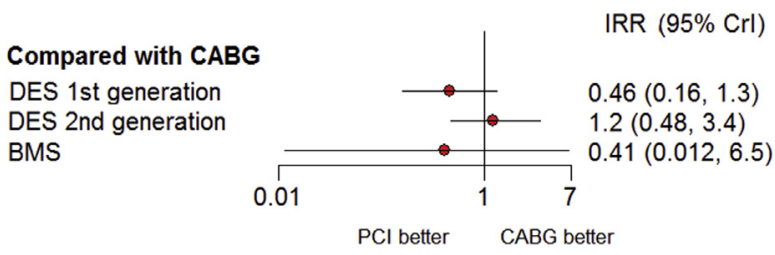

FIGURE 3. NMA estimates for individual component of death, MI, or stroke at latest follow-up (expressed as IRR, with relative 95\% CrI) for different stent generations. DES first-generation include PES and SES; DES second-generation include Bio-ES, EES, and ZES. CABG as comparator. $C A B G$, Coronary artery bypass grafting; $D E S$, drug-eluting stents; $B M S$, bare metal stent; $P C I$, percutaneous coronary intervention; $I R R$, incidence rate ratio; $C r I$, credible interval; $M I$, myocardial infarction.

second-generation DES (hazard ratio, 1.79; 95\% CI, 1.422.2) presented comparable IRRs for repeat revascularization when compared with CABG (Figure E9).

\section{DISCUSSION}

NMA combines direct and indirect evidence for particular pairwise comparisons, thereby synthesizing a greater share of the available evidence than a traditional metaanalysis. The results from indirect evidence combined with the direct evidence may strengthen the assessment between treatments directly evaluated. Although the evidence networks underlying NMA typically include RCTs, randomization does not hold across trials and there is a residual risk of confounding bias, compromising internal validity.

The main finding of the present NMA was that the introduction of second-generation DESs did not improve PCI outcomes when compared with $\mathrm{CABG}$ for unprotected LMD. Second-generation DESs (EES, ZES, and Bio-ES)

\section{Death/MI/stroke}

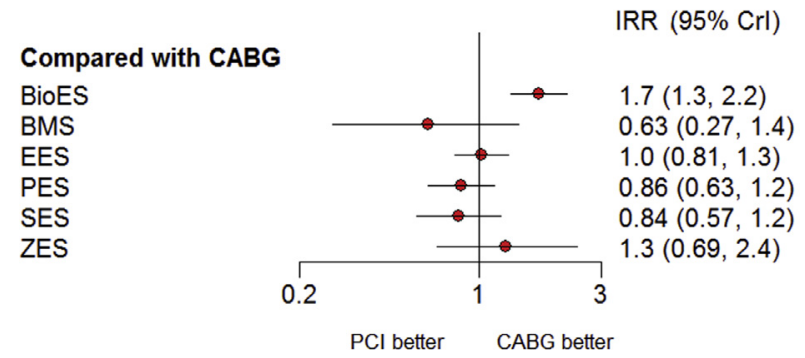

Revascularization

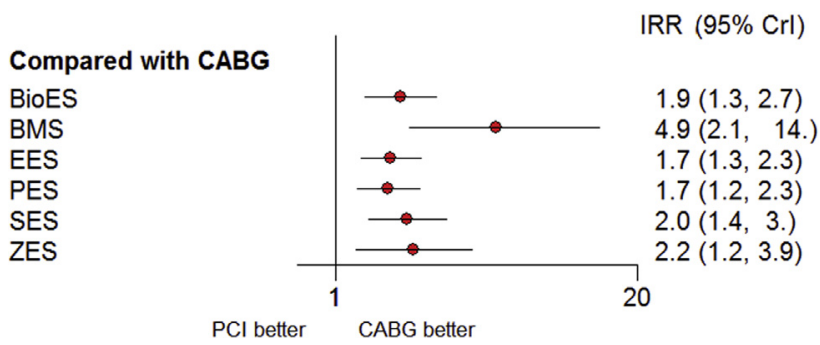

FIGURE 4. NMA estimates for the primary end points at latest follow-up (expressed as IRR, with relative $95 \% \mathrm{CrI}$ ) for different stent types CABG as comparator. $M I$, Myocardial infarction; $C A B G$, coronary artery bypass grafting; Bio-ES, biolimus-eluting stent; BMS, bare metal stent; EES, everolimus-eluting stent; PES, paclitaxel-eluting stents; SES, sirolimuseluting stents; $Z E S$, zotarolimus-eluting stent; $P C I$, percutaneous coronary intervention; $I R R$, incidence rate ratio; $C r I$, credible interval.

were associated with a significant trend toward an increased risk of death/MI/stroke when compared with $\mathrm{CABG}$, although this was not observed with BMS or firstgeneration stents (SES and PES). When outcomes from individual stents were analyzed separately, we found that the Bio-ES was associated with a significant 3-fold increased risk of MI, ZES showed a nonsignificant trend toward an increased risk of mortality, and MI and EES showed a marginally nonsignificant increased risk of mortality.

Although the introduction of first-generation DESs narrowed the gap between CABG and PCI in terms of repeat revascularization when compared with BMS, the risk of a further reintervention did not further improve with second-generation DESs. Concern about the long-term safety of DESs for unprotected LMD has been raised in the past because of the observed risk of stent thrombosis, which may outweigh the benefits of DESs. ${ }^{19-21}$ The SYNTAX trial $^{3}$ and PRECOMBACT trial ${ }^{9}$ showed comparable results between first-generation DESs and CABG for unprotected LMD, but these studies were largely underpowered to detect differences in hard clinical end points such as death and MI. New-generation DES, including polymer Bio-ES and EES, have been introduced to replace firstgeneration DES with more biocompatible and thinner 

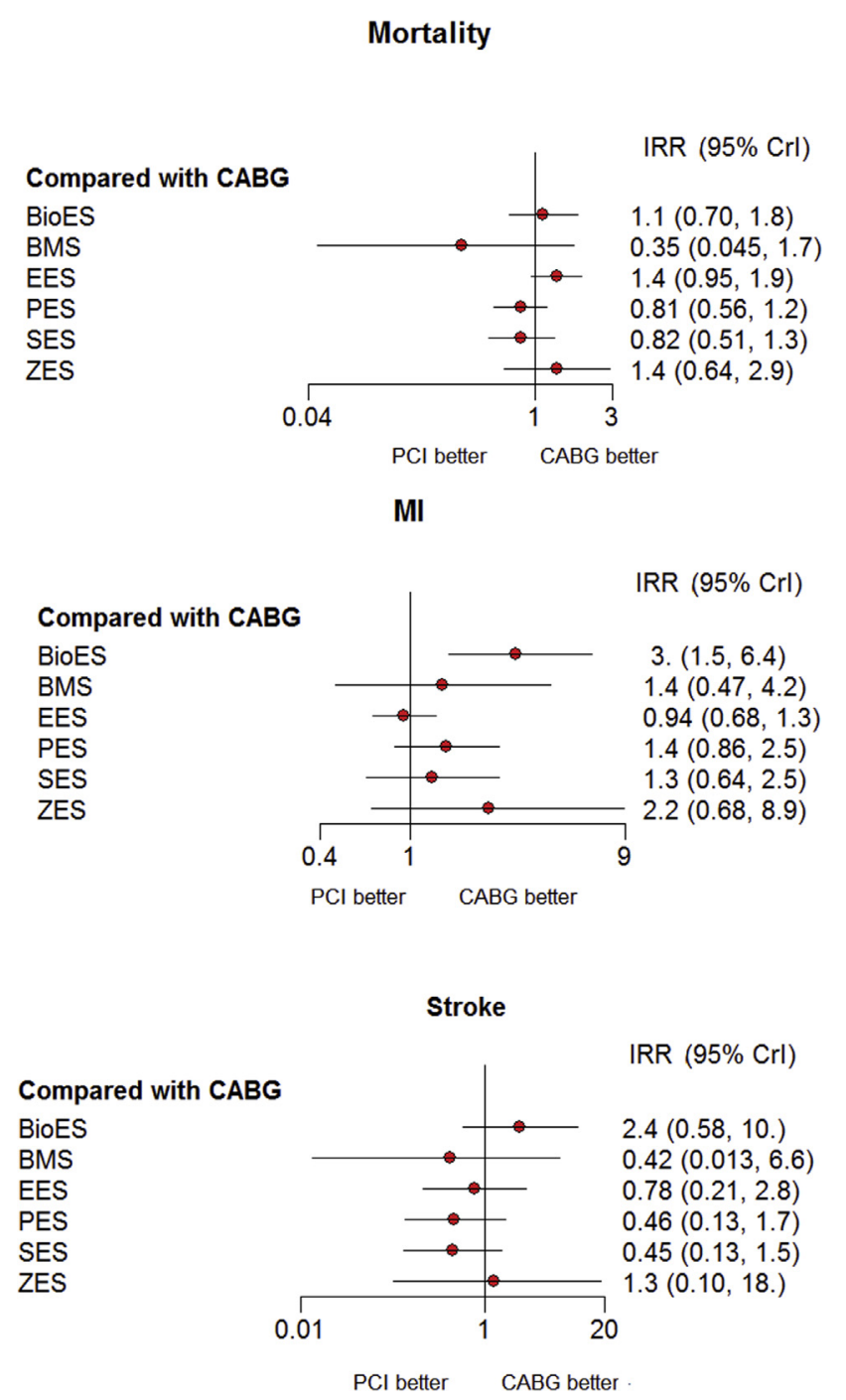

FIGURE 5. NMA estimates for individual component of death, MI, or stroke at latest follow-up (expressed as IRR, with relative $95 \% \mathrm{CrI}$ ) for different stent types. CABG as comparator. $C A B G$, Coronary artery bypass grafting; Bio-ES, biolimus-eluting stent; $B M S$, bare metal stent; EES, everolimus-eluting stent; $P E S$, paclitaxel-eluting stents; $S E S$, sirolimuseluting stents; $Z E S$, zotarolimus-eluting stent; $P C I$, percutaneous coronary intervention; $I R R$, incidence rate ratio; $C r I$, credible interval; $M I$, myocardial infarction.

polymers to reduce stent thrombosis rates. ${ }^{21}$ However, 2 recent large RCTs, NOBLE ${ }^{1}$ and EXCEL, ${ }^{2}$ compared Bio-ES and EES, respectively, with CABG, reaching conflicting conclusions about the noninferiority of PCI over CABG. Such a discrepancy can be partially related to different definitions adopted for MI. For the primary end point definition, the NOBLE trial included nonprocedural MI only, whereas EXCEL, SYNTAX, and PRECOMBAT included both procedural and subsequent spontaneous MI. However, PCI-related MI has a greater impact on longterm prognosis than CABG-related MI, and there is still controversy on which unifying common definition for PCI-related and CABG-related MI should be adopted. ${ }^{22}$ This aspect calls into question the validity of end point definitions, which include periprocedural $\mathrm{MI}$ in the comparison between PCI and CABG. Of note, in EXCEL, although the 2 strategies did not differ for the composite of procedural and spontaneous MI, PCI was associated with an increased risk of subsequent spontaneous MI when compared with CABG.

Although second-generation DESs have been reported to improve PCI outcomes achieved with first-generation DESs by reducing the risk of stent thrombosis and restenosis, ${ }^{23}$ in most available comparisons, the distal targets were treated. We can speculate that the superiority of second-generation over first-generation DESs might not be reproducible in LMD. It has been shown that the risk of restenosis might be less relevant in case of coronary arteries with larger diameter $(\geq 3.5 \mathrm{~mm}),{ }^{24}$ and this aspect can partially explain the lack of benefit in terms of repeat revascularization with second-generation DES observed in the present NMA.

On the other hand, the Bio-ES has been perceived as safer than the first-generation DES, mainly on the basis of results from individual trials powered only for composite end points of safety and efficacy. ${ }^{25}$ However, a recent landmark NMA ${ }^{26}$ concluded that the Bio-ES is associated with an excess of death and MI when compared with other stents. Biodegradable polymer DESs, such as Bio-ES, use polymers that dissolve after time and antiproliferative drug elution is needed. Once the degradation process of the polymer is completed in these devices, what remains is a bare-metal scaffold with a thick-strut design. This platform may provide lower elasticity than durable polymers, with an increased risk of fragility and micro-damage to the coating, and potential "jailing" of side branches. These factors explain the lower safety profile with biolimus biodegradable polymer stents. ${ }^{26}$

\section{Study Limitations}

As with any meta-analysis, our report shares the limitations of the original studies. By exploiting potentially complex evidence networks along with indirect and direct comparisons, NMA assumes that patients enrolled in the component studies were sampled from the same theoretical population and that similar comparators between different trials have a consistent risk-benefit ratio.

In the present analysis, some studies have a limited sample size, and there was a relatively small number of trials for the comparison of individual stents against CABG. As a consequence, few comparisons present relatively wide confidence interval (unaddressed uncertainty). However, no inconsistencies were apparent between the direct and indirect estimates for the end points considered across all comparisons, which provides strong scientific support for the reliability of the network. Results were analyzed on aggregate data, and therefore we could not assess whether 
all baseline characteristics were balanced between the groups. Finally, several comparisons were of borderline statistical significance, and even greater numbers of patients with longer-term follow-up would add greater precision to the present results.

\section{CONCLUSIONS}

A word of caution should be noted on the current trend of preferring PCI with new-generation DESs over CABG for LMD in view of the present findings. We could not demonstrate the anticipated benefit from second-generation DESs in this population in terms of mortality, MI, and repeat revascularization. The routine use of new-generation DESs in the treatment of LMD still deserves further investigations. Current trials are largely underpowered to clarify whether DESs are as safe as CABG in terms of mortality, and the use of end points including procedural MI might have masked potential risks with DESs. Adequately powered and well-designed studies are needed to guide clinicians in decision-making. Finally, concerns remain because most clinical research studies are funded by manufacturers with the relative risk of bias in favor of new devices.

\section{Conflict of Interest Statement}

Authors have nothing to disclose with regard to commercial support.

\section{References}

1. Mäkikallio T, Holm NR, Lindsay M, Spence MS, Erglis A, Menown IB, et al. Percutaneous coronary angioplasty versus coronary artery bypass grafting in treatment of unprotected left main stenosis (NOBLE): a prospective, randomised, open-label, non-inferiority trial. Lancet. 2016;388:2743-52.

2. Stone GW, Sabik JF, Serruys PW, Simonton CA, Généreux P, Puskas J, et al. Everolimus-eluting stents or bypass surgery for left main coronary artery disease. N Engl J Med. 2016:375:2223-35.

3. Morice MC, Serruys PW, Kappetein AP, Feldman TE, Ståhle E, Colombo A, et al. Five-year outcomes in patients with left main disease treated with either percutaneous coronary intervention or coronary artery bypass grafting in the synergy between percutaneous coronary intervention with taxus and cardiac surgery trial. Circulation. 2014;129:2388-94.

4. Liberati A, Altman DG, Tetzlaff J, Mulrow C, Gøtzsche PC, Ioannidis JP, et al. The PRISMA statement for reporting systematic reviews and meta-analyses of studies that evaluate health care interventions: explanation and elaboration. Ann Intern Med. 2009;151:W65-94.

5. Hutton B, Salanti G, Caldwell DM, Chaimani A, Schmid CH, Cameron C, et al. The PRISMA extension statement for reporting of systematic reviews incorporating network meta-analyses of health care interventions: checklist and explanations. Ann Intern Med. 2015;162:777-84.

6. Yadav M, Palmerini T, Caixeta A, Madhavan MV, Sanidas E, Kirtane AJ, et al. Prediction of coronary risk by SYNTAX and derived scores: synergy between percutaneous coronary intervention with taxus and cardiac surgery. J Am Coll Cardiol. 2013;62:1219-30.

7. Higgins JP, Altman DG, Gøtzsche PC, Jüni P, Moher D, Oxman AD, et al. The Cochrane Collaboration's tool for assessing risk of bias in randomised trials. BMJ. 2011;343:d5928.
8. Dias S, Sutton AJ, Ades AE, Welton NJ. Evidence synthesis for decision making 2: a generalized linear modeling framework for pairwise and network meta-analysis of randomized controlled trials. Med Decis Making. 2013;33:607-17.

9. Cipriani A, Higgins JP, Geddes JR, Salanti G. Conceptual and technical challenges in network meta-analysis. Ann Intern Med. 2013;159:130-7.

10. Brooks S, Gelman A. General methods for monitoring convergence of iterative simulations. J Comput Graph Stat. 1998;7:434-55.

11. Gelman A, Jakulin A, Pittau MG, Su YS. A weakly informative default prior distribution for logistic and other regression models. Ann Appl Stat. 2008;2: 1360-83.

12. Dias S, Welton NJ, Caldwell DM, Ades AE. Checking consistency in mixed treatment comparison meta-analysis. Stat Med. 2010;29:932-44.

13. Ahn JM, Roh JH, Kim YH, Park DW, Yun SC, Lee PH, et al. Randomized trial of stents versus bypass surgery for left main coronary artery disease: 5-year outcomes of the PRECOMBAT Study. J Am Coll Cardiol. 2015;65:2198-206.

14. Boudriot E, Thiele H, Walther T, Liebetrau C, Boeckstegers P, Pohl T, et al. Randomized comparison of percutaneous coronary intervention with sirolimuseluting stents versus coronary artery bypass grafting in unprotected left main stem stenosis. J Am Coll Cardiol. 2011;57:538-45.

15. Buszman PE, Kiesz SR, Bochenek A, Peszek-Przybyla E, Szkrobka I, Debinski M, et al. Acute and late outcomes of unprotected left main stenting in comparison with surgical revascularization. J Am Coll Cardiol. 2008;51: 538-45.

16. Erglis A, Narbute I, Kumsars I, Jegere S, Mintale I, Zakke I, et al. A randomized comparison of paclitaxel-eluting stents versus bare-metal stents for treatment of unprotected left main coronary artery stenosis. J Am Coll Cardiol. 2007;50:491-7.

17. Mehilli J, Kastrati A, Byrne RA, Bruskina O, Iijima R, Schulz S, et al. Paclitaxelversus sirolimus-eluting stents for unprotected left main coronary artery disease. J Am Coll Cardiol. 2009;53:1760-8.

18. Mehilli J, Richardt G, Valgimigli M, Schulz S, Singh A, Abdel-Wahab M, et al Zotarolimus- versus everolimus-eluting stents for unprotected left main coronary artery disease. J Am Coll Cardiol. 2013;62:2075-82.

19. Mauri L, Hsieh WH, Massaro JM, Ho KK, D’Agostino R, Cutlip DE. Stent thrombosis in randomized clinical trials of drug-eluting stents. $N$ Engl J Med. 2007;356:1020-9.

20. Kuchulakanti PK, Chu WW, Torguson R, Ohlmann P, Rha SW, Clavijo LC et al. Correlates and long-term outcomes of angiographically proven sten thrombosis with sirolimus- and paclitaxel-eluting stents. Circulation. 2006; 113:1108-13.

21. Farb A, Boam AB. Stent thrombosis redux: the FDA perspective. $N$ Engl J Med 2007;356:984-7.

22. Cho MS, Ahn JM, Lee CH, Kang DY, Lee JB, Lee PH, et al. Differential rates and clinical significance of periprocedural myocardial infarction after stenting or bypass surgery for multivessel coronary disease according to various definitions. JACC Cardiovasc Interv. 2017;10:1498-507.

23. Palmerini T, Benedetto U, Biondi-Zoccai G, Della Riva D, Bacchi-Reggiani L, Smits PC, et al. Long-term safety of drug-eluting and bare-metal stents: evidence from a comprehensive network meta-analysis. J Am Coll Cardiol. 2015;65: 2496-507.

24. Steinberg DH, Mishra S, Javaid A, Slottow TL, Buch AN, Roy P, et al. Comparison of effectiveness of bare metal stents versus drug-eluting stents in large ( $>$ or $=3.5 \mathrm{~mm}$ ) coronary arteries. Am J Cardiol. 2007;99:599-602.

25. Natsuaki M, Kozuma K, Morimoto T, Kadota K, Muramatsu T, Nakagawa Y et al. Biodegradable polymer biolimus-eluting stent versus durable polymer everolimus-eluting stent: a randomized, controlled, noninferiority trial. J Am Coll Cardiol. 2013;62:181-90.

26. Navarese EP, Tandjung K, Claessen B, Andreotti F, Kowalewski M, Kandzari DE, et al. Safety and efficacy outcomes of first and second generation durable polymer drug eluting stents and biodegradable polymer biolimus eluting stents in clinical practice: comprehensive network meta-analysis. BMJ. 2013; 347:f6530.

Key Words: coronary artery bypass grafting, percutaneous coronary intervention, coronary stenting, left main disease 


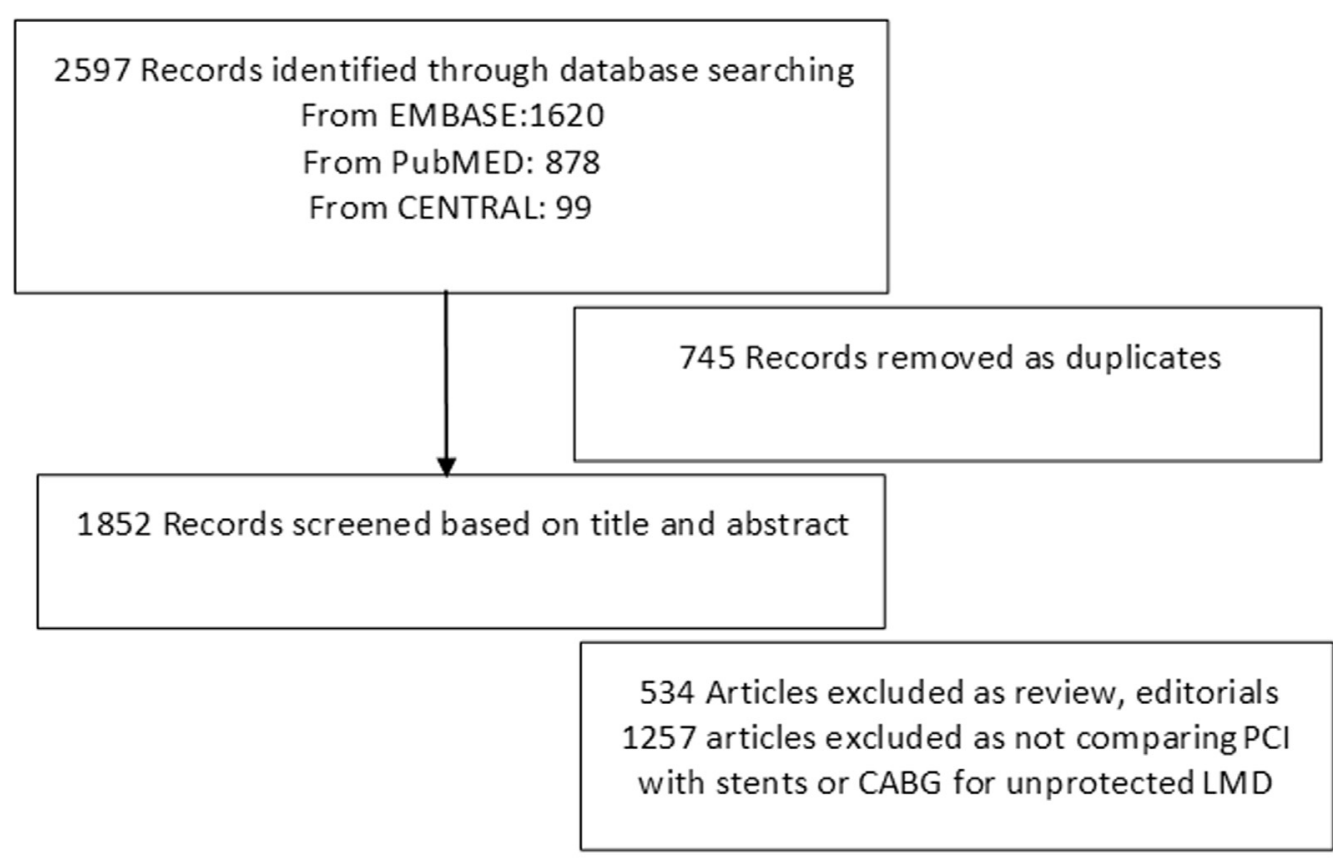

61 Full-text articles assessed for eligibility

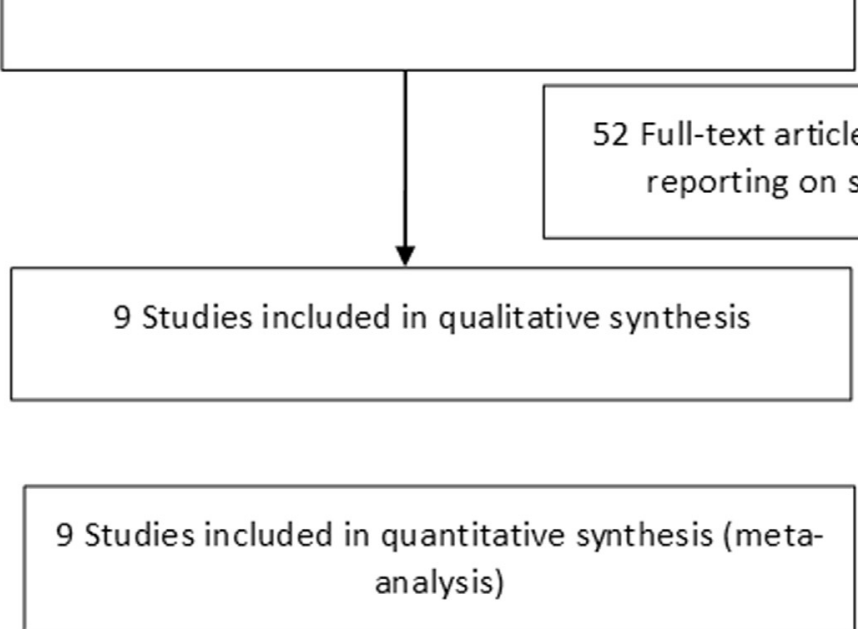

FIGURE E1. Flow diagram of study selection. CENTRAL, Cochrane Central Register of Controlled Trials; PCI, percutaneous coronary intervention; $C A B G$, coronary artery bypass grafting; $L M D$, left main disease; $R C T$, randomized controlled trial. 

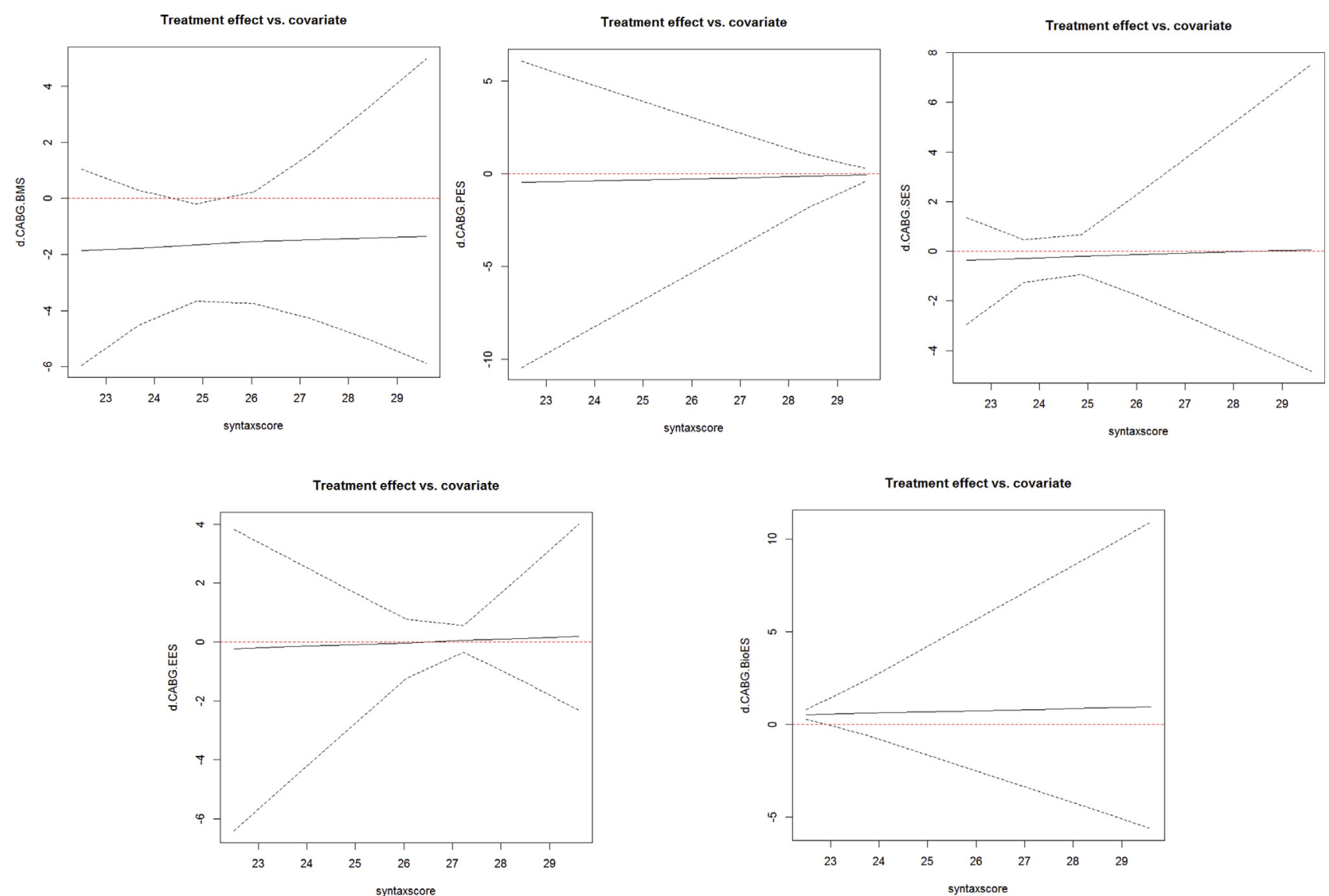

FIGURE E2. SYNTAX score has no effect on treatment effect (stents vs CABG) for the composite of death/MI/stroke (no variation across syntax score values). $C A B G$, Coronary artery bypass grafting; $B M S$, bare metal stent; $P E S$, paclitaxel-eluting stent; $S E S$, sirolimus-eluting stent; $E E S$, everolimus-eluting stent; Bio-ES, biolimus-eluting stent. 

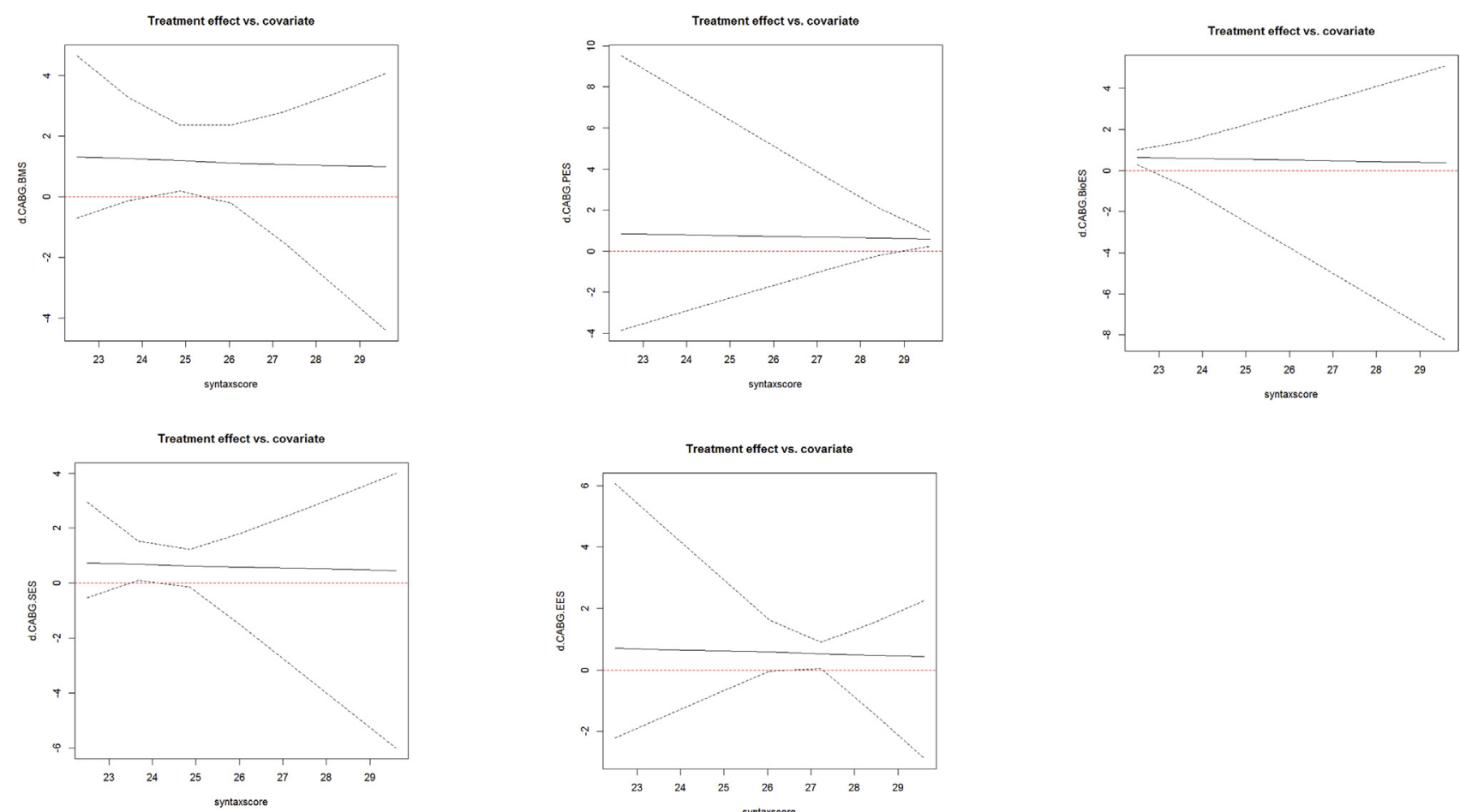

FIGURE E3. SYNTAX score has no effect on treatment effect (stents vs CABG) for repeat revascularization (no variation across syntax score values). $C A B G$, Coronary artery bypass grafting; $B M S$, bare metal stent; $P E S$, paclitaxel-eluting stent; Bio-ES, biolimus-eluting stent; $S E S$, sirolimus-eluting stent; $E E S$, everolimus-eluting stent.

Inconsistency check: Node split

death/MI/stroke

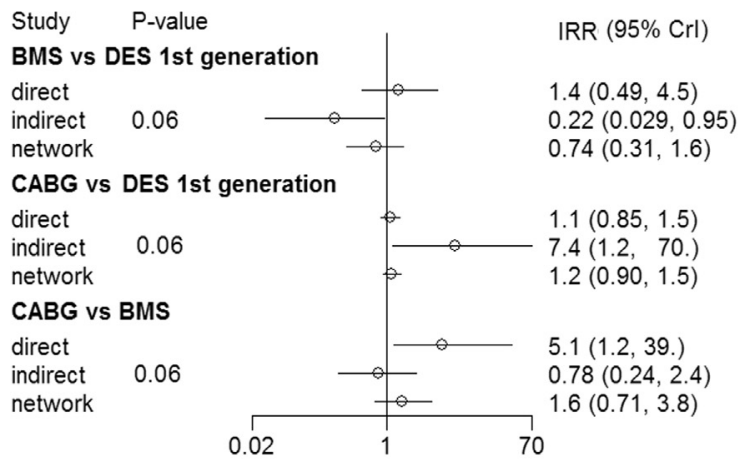

Revascularization

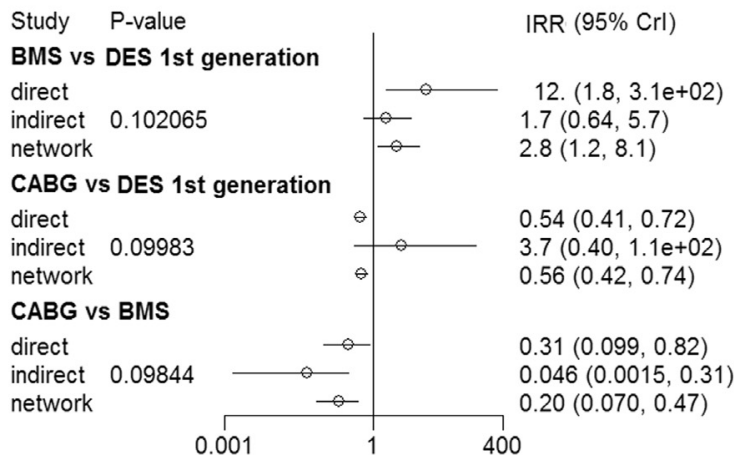

FIGURE E4. Comparison of direct and indirect estimates to assess inconsistency for the primary end points (expressed as IRR, with relative $95 \% \mathrm{CrI}$ ) for different stent generations (DES first-generation include PES and SES; DES second-generation include Bio-ES, EES, and ZES). MI, Myocardial infarction; $I R R$, incidence rate ratio; $C r I$, credible interval; $B M S$, bare metal stent; $D E S$, drug-eluting stent; $C A B G$, coronary artery bypass grafting. 


\section{Inconsistency check: node split}

Mortality
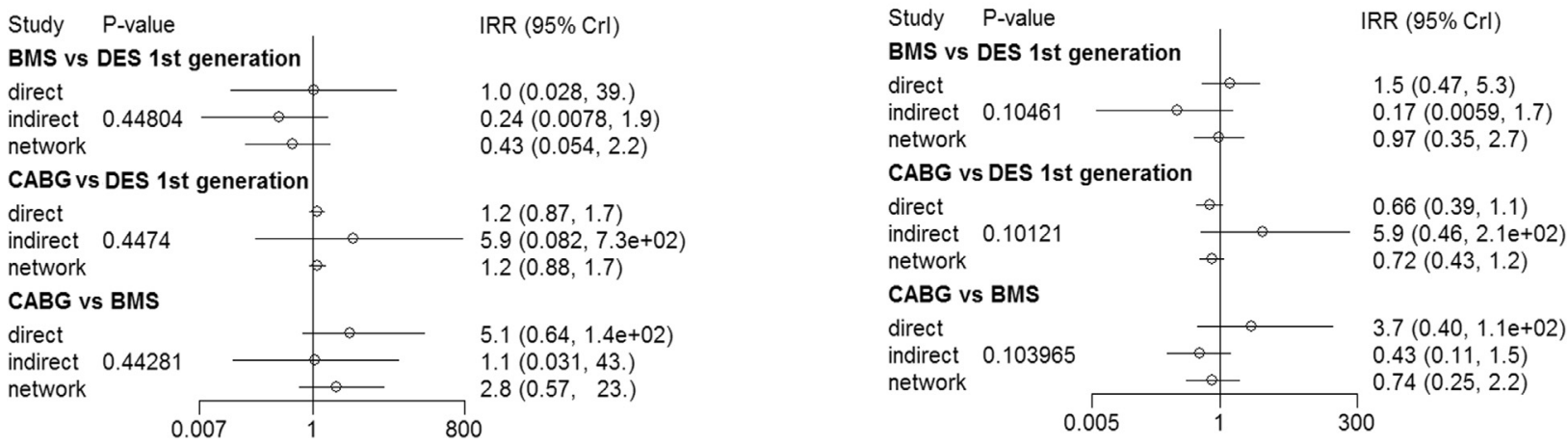

FIGURE E5. Comparison of direct and indirect estimates to assess inconsistency for individual component of death and MI (expressed as IRR, with relative $95 \%$ CrI) for different stent generations (DES first-generation include PES and SES; DES second-generation include Bio-ES, EES, and ZES). No computation for stroke because Erglis and colleagues ${ }^{16}$ did not report stroke rate. IRR, Incidence rate ratio; $C r I$, credible interval; BMS, bare metal stent; $D E S$, drug-eluting stent; $C A B G$, coronary artery bypass grafting; $M I$, myocardial infarction.

\section{Inconsistency check: Node split}

death/MI/stroke

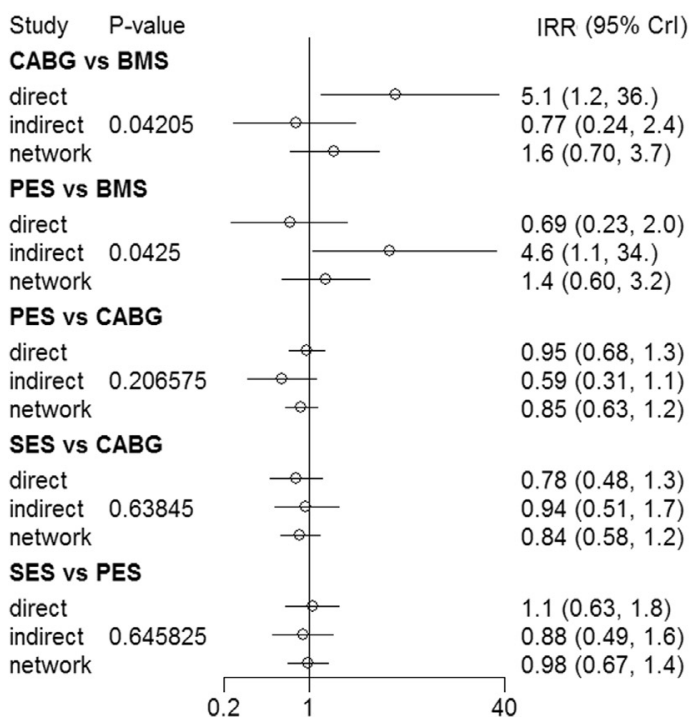

Revascularization

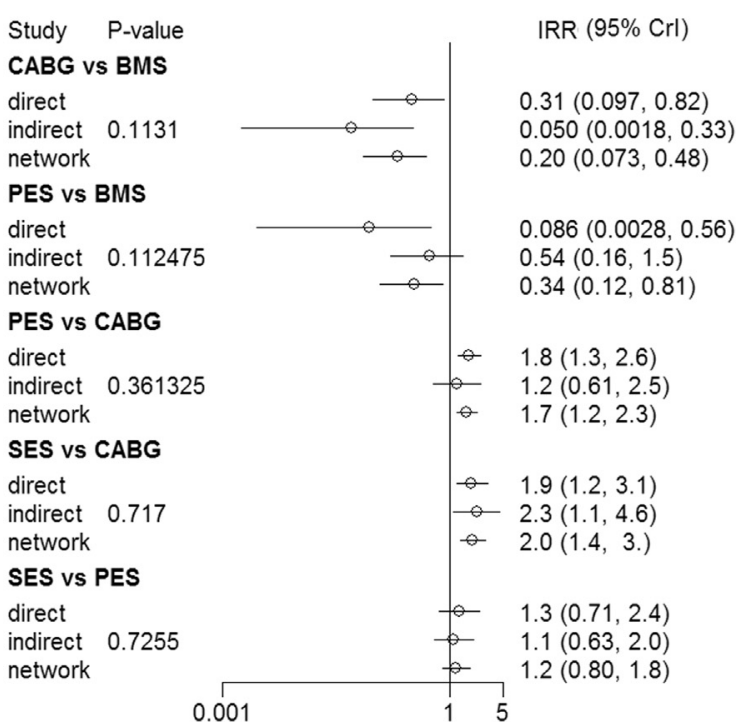

FIGURE E6. Comparison of direct and indirect estimates to assess inconsistency for the primary end points (expressed as IRR, with relative $95 \%$ CrI) for different stent types. $M I$, Myocardial infarction; $I R R$, incidence rate ratio; $C r I$, credible interval; $C A B G$, coronary artery bypass grafting; $B M S$, bare metal stent; PES, paclitaxel-eluting stent; SES, sirolimus-eluting stent. 
Inconsistency check: Node split
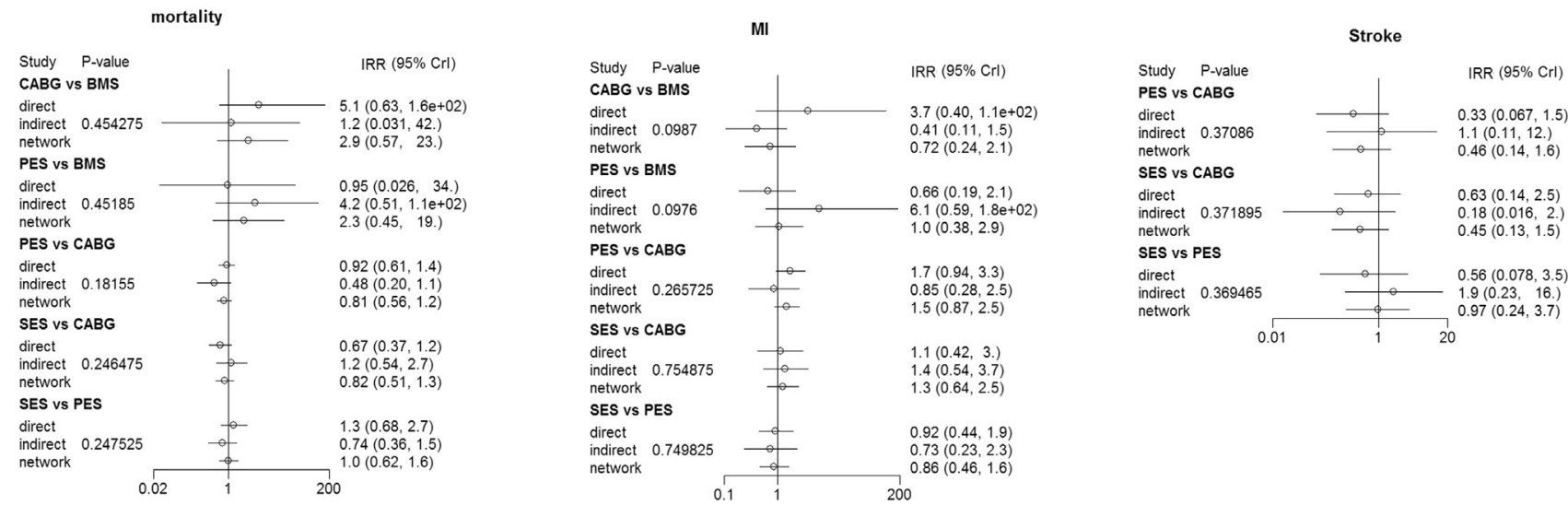

FIGURE E7. Comparison of direct and indirect estimates to assess inconsistency for individual component of death, MI, or stroke at latest follow-up (expressed as IRR, with relative $95 \% \mathrm{CrI}$ ) for different stent types. IRR, Incidence rate ratio; $C r I$, credible interval; $C A B G$, coronary artery bypass grafting; $B M S$, bare metal stent; PES, paclitaxel-eluting stent; SES, sirolimus-eluting stent; $M I$, myocardial infarction.

\section{Death/MI/stroke}

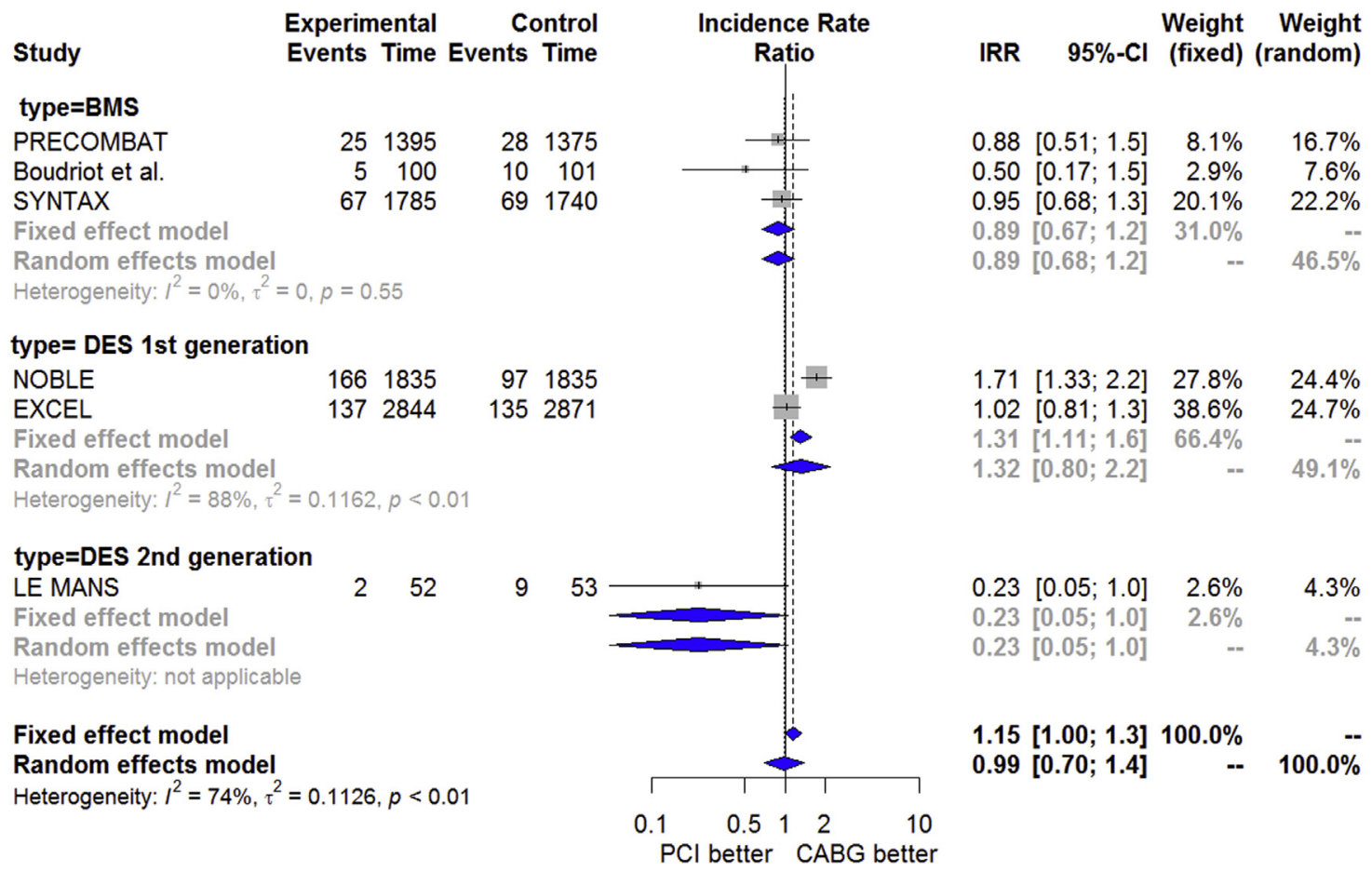

FIGURE E8. Pairwise pooled and subgroup meta-analysis for the composite of death/MI/stroke with BMS and first- and second-generation DESs (firstgeneration DESs include PES and SES; second-generation DESs include Bio-ES, EES, and ZES). CABG as comparator. MI, Myocardial infarction; IRR, incidence rate ratio; $C I$, confidence interval; BMS, bare metal stent; PRECOMBAT, Premier of Randomized Comparison of Bypass Surgery versus Angioplasty Using Sirolimus-Eluting Stent in Patients with Left Main Coronary Artery Disease trial; SYNTAX, Synergy between Percutaneous Coronary Intervention with Taxus and Cardiac Surgery trial; DES, drug-eluting stent; NOBLE, Nordic-Baltic-British left main revascularisation study; EXCEL, Evaluation of XIENCE versus Coronary Artery Bypass Surgery for Effectiveness of Left Main Revascularization trial; LE MANS, Study of Unprotected Left Main Stenting Versus Bypass Surgery; $P C I$, percutaneous coronary intervention; $C A B G$, coronary artery bypass grafting. 


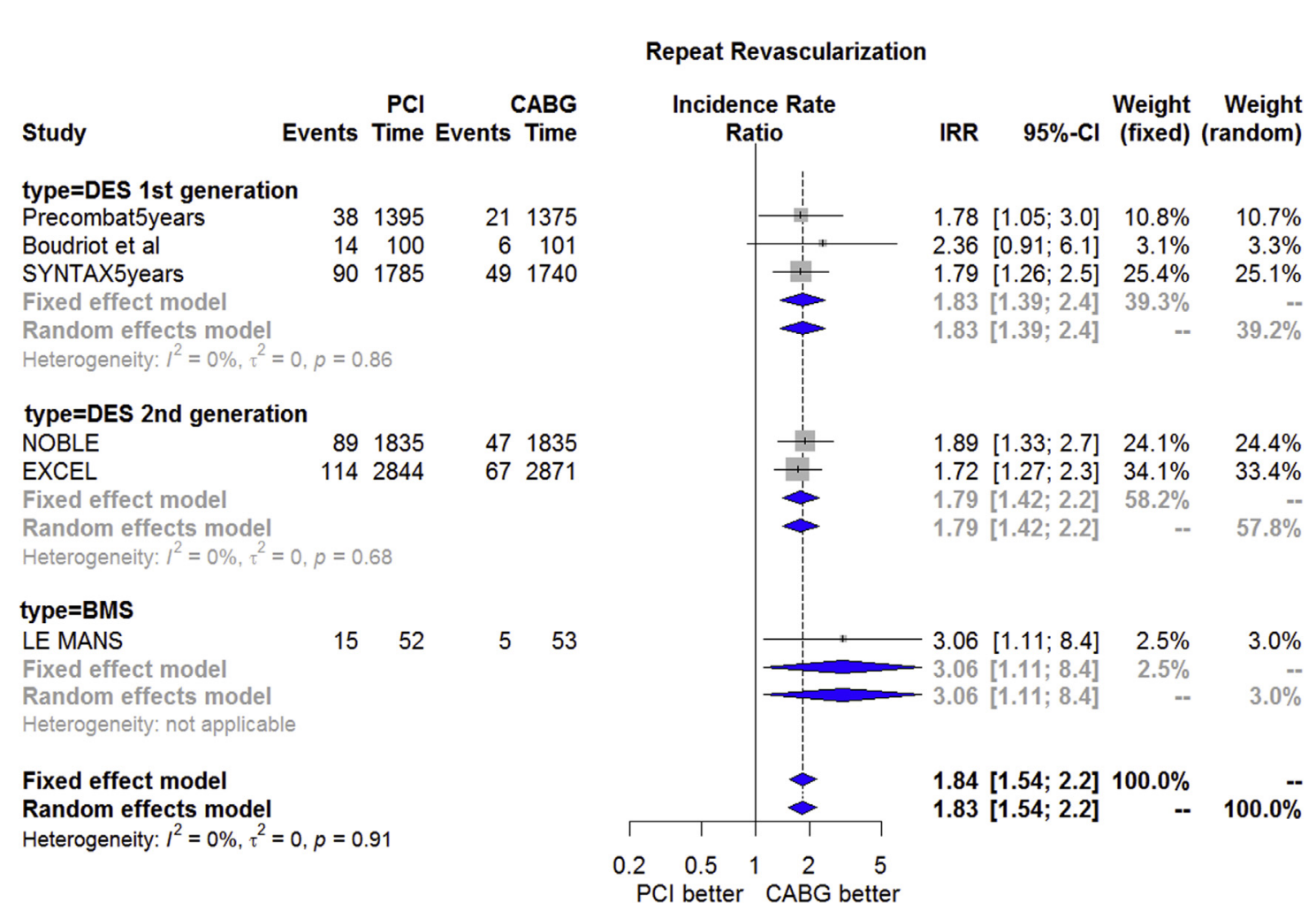

FIGURE E9. Pairwise pooled and subgroup meta-analysis for repeat revascularization with BMS and first- and second-generation DESs (first-generation DESs include PES and SES; second-generation DESs include Bio-ES, EES, and ZES). CABG as comparator. PCI, Percutaneous coronary intervention; $C A B G$, coronary artery bypass grafting; IRR, incidence rate ratio; $C I$, confidence interval; DES, drug-eluting stent; PRECOMBAT, Premier of Randomized Comparison of Bypass Surgery versus Angioplasty Using Sirolimus-Eluting Stent in Patients with Left Main Coronary Artery Disease trial; SYNTAX, Synergy between Percutaneous Coronary Intervention with Taxus and Cardiac Surgery trial; NOBLE, Nordic-Baltic-British left main revascularisation study; EXCEL, Evaluation of XIENCE versus Coronary Artery Bypass Surgery for Effectiveness of Left Main Revascularization trial; $B M S$, bare metal stent; LE MANS, Study of Unprotected Left Main Stenting Versus Bypass Surgery. 
TABLE E1. Main inclusion and exclusion criteria, primary and secondary end points of randomized controlled trials

\begin{tabular}{|c|c|c|c|c|}
\hline Trial & Main inclusion criteria & Main exclusion criteria & Primary end point & Secondary end point \\
\hline NOBLE & $\begin{array}{l}\text { Stable angina pectoris, unstable } \\
\text { angina pectoris, or acute } \\
\text { coronary syndrome, together } \\
\text { with a lesion with visually } \\
\text { assessed stenosis diameter } \\
\geq 50 \% \text { or fractional flow } \\
\text { reserve } \leq 0.80 \text { in the left main } \\
\text { coronary artery ostium, mid- } \\
\text { shaft, or bifurcation, with no } \\
\text { more than } 3 \text { additional } \\
\text { noncomplex lesions. }\end{array}$ & $\begin{array}{l}\text { ST-elevation infarction within } \\
24 \mathrm{~h} \text {, being considered too } \\
\text { high risk for CABG or PCI, or } \\
\text { expected survival of }<1 \mathrm{y} \text {. }\end{array}$ & $\begin{array}{l}\text { Composite of MACCE; death } \\
\text { from any cause, } \\
\text { nonprocedural MI, repeat } \\
\text { revascularization, or stroke. }\end{array}$ & $\begin{array}{l}\text { The individual component of } \\
\text { the primary MACCE end } \\
\text { point, definite stent } \\
\text { thrombosis, and symptomatic } \\
\text { graft occlusion. Procedural } \\
\text { MIs were documented (post } \\
\text { hoc). Repeat } \\
\text { revascularizations. }\end{array}$ \\
\hline EXCEL & $\begin{array}{l}\text { Stenosis of the left main } \\
\text { coronary artery of } \geq 70 \% \text {, as } \\
\text { estimated visually, or stenosis } \\
\text { of } 50 \% \text { to }<70 \% \text { if } \\
\text { determined by means of } \\
\text { noninvasive or invasive } \\
\text { testing to be } \\
\text { hemodynamically } \\
\text { significant, and a consensus } \\
\text { among the members of the } \\
\text { heart team regarding } \\
\text { eligibility for } \\
\text { revascularization with PCI or } \\
\text { CABG. In addition, } \\
\text { participants were required to } \\
\text { have low-to-intermediate } \\
\text { anatomic complexity of } \\
\text { coronary artery disease, as } \\
\text { defined by a site-determined } \\
\text { SYNTAX score of } \leq 32 \text { (the } \\
\text { SYNTAX score reflects a } \\
\text { comprehensive angiographic } \\
\text { assessment of the coronary } \\
\text { vasculature, with } 0 \text { as the } \\
\text { lowest score and higher } \\
\text { scores [no upper limit] } \\
\text { indicating more complex } \\
\text { coronary anatomy). }\end{array}$ & $\begin{array}{l}\text { Prior PCI of the left main trunk } \\
\text { at any time before } \\
\text { randomization, PCI of any } \\
\text { other (nonleft main) coronary } \\
\text { artery lesions within } 1 \mathrm{y} \\
\text { before randomization, CABG } \\
\text { at any time before } \\
\text { randomization. Need for any } \\
\text { concomitant cardiac surgery } \\
\text { other than CABG. } \\
\text { Angiographic exclusion } \\
\text { criteria: a. Left main diameter } \\
\text { stenosis }<50 \%, \text { unless left } \\
\text { main equivalent disease is } \\
\text { present; b. SYNTAX score } \\
\geq 33 \text {, as determined by the } \\
\text { local Heart Team; c. Visually } \\
\text { estimated left main reference } \\
\text { vessel diameter }<2.25 \text { mm or } \\
>4.25 \text { mm; d. The presence } \\
\text { of specific coronary lesion } \\
\text { characteristics or other } \\
\text { cardiac conditions that lead } \\
\text { the participating } \\
\text { interventional cardiologist or } \\
\text { cardiac surgeon to believe } \\
\text { that clinical equipoise is not } \\
\text { present }\end{array}$ & $\begin{array}{l}\text { The primary composite end } \\
\text { point of death from any } \\
\text { cause, stroke, or MI }\end{array}$ & $\begin{array}{l}\text { A composite of death from any } \\
\text { cause, stroke, or MI at } 30 \mathrm{~d} \\
\text { and the rate of a composite of } \\
\text { death, stroke, MI, or } \\
\text { ischemia-driven } \\
\text { revascularization at } 3 \mathrm{y} \text {. } \\
\text { Additional secondary end } \\
\text { points included the } \\
\text { components of the primary } \\
\text { end point, revascularization, } \\
\text { stent thrombosis, } \\
\text { symptomatic graft stenosis or } \\
\text { occlusion, bleeding } \\
\text { complications, and a } \\
\text { prespecified composite of } \\
\text { periprocedural MAEs. }\end{array}$ \\
\hline LE MANS & $\begin{array}{l}\text { Patients with }>50 \% \text { narrowing } \\
\text { of ULMCA, with or without } \\
\text { multivessel coronary artery } \\
\text { disease suitable for equal } \\
\text { revascularization both with } \\
\text { PCI and CABG. All patients } \\
\text { had to be symptomatic with } \\
\text { documented myocardial } \\
\text { ischemia. }\end{array}$ & $\begin{array}{l}\text { Acute MI, total occlusion of left } \\
\text { main, comorbid conditions, } \\
\text { or coronary anatomic } \\
\text { considerations that increased } \\
\text { the surgical risk to a } \\
\text { euroSCORE of } \geq 8 \text {, stroke or } \\
\text { transient ischemic attack } \\
\text { within } 3 \text { mo, renal } \\
\text { dysfunction, or } \\
\text { contraindication to } \\
\text { antiplatelet therapy. }\end{array}$ & $\begin{array}{l}\text { The change in LVEF assessed } \\
\text { by } 2 \text {-dimensional } \\
\text { echocardiography } 12 \mathrm{mo}\end{array}$ & $\begin{array}{l}\text { MACCE, other MAE, length of } \\
\text { hospitalization, exercise } \\
\text { tolerance measured with an } \\
\text { electrocardiographic } \\
\text { treadmill stress test along } \\
\text { with angina severity } \\
\text { according to the Canadian } \\
\text { Cardiovascular Society } \\
\text { classification after } 1 \mathrm{y} \text {, total } \\
\text { survival, TVF, and TVR. }\end{array}$ \\
\hline
\end{tabular}


TABLE E1. Continued

\begin{tabular}{|c|c|c|c|c|}
\hline Trial & Main inclusion criteria & Main exclusion criteria & Primary end point & Secondary end point \\
\hline PRECOMBAT & $\begin{array}{l}\text { Age }>18 \text { y and had received a } \\
\text { diagnosis of stable angina, } \\
\text { unstable angina, silent } \\
\text { ischemia, or non-ST-segment } \\
\text { elevation MI. All patients had } \\
\text { newly diagnosed ULMCA } \\
\text { stenosis ( }>50 \% \text { diameter } \\
\text { stenosis by visual } \\
\text { angiographic estimation) and } \\
\text { had been judged to be } \\
\text { suitable candidates for PCI or } \\
\text { CABG. }\end{array}$ & $\begin{array}{l}\text { Systemic (IV) sirolimus use } \\
\text { within } 12 \text { mo. Any previous } \\
\text { PCI within } 1 \text { y. Previous } \\
\text { bypass surgery. Any previous } \\
\text { PCI of a ULMCA or ostial } \\
\text { left circumflex artery or ostial } \\
\text { left anterior descending } \\
\text { artery lesion within } 1 \mathrm{y} \text {. } \\
\text { Acute MI within } 1 \mathrm{wk} \text {. } \\
\text { Ejection fraction }<30 \% \text {. } \\
\text { Cardiogenic shock. }\end{array}$ & $\begin{array}{l}\text { Composite of death from any } \\
\text { cause, MI, stroke, or } \\
\text { ischemia-driven TVR }\end{array}$ & $\begin{array}{l}\text { The individual components of } \\
\text { the primary end point; a } \\
\text { composite of death, MI, or } \\
\text { stroke, and clinically driven } \\
\text { TVR. }\end{array}$ \\
\hline SYNTAX & $\begin{array}{l}\text { De novo lesions, } \geq 50 \% \text { target } \\
\text { vessel stenosis with stable/ } \\
\text { unstable angina or atypical } \\
\text { chest pain. If asymptomatic, } \\
\text { positive evidence of } \\
\text { myocardial ischemia was } \\
\text { required. }\end{array}$ & $\begin{array}{l}\text { Previous PCI or CABG, acute } \\
\text { MI, or the need for } \\
\text { concomitant cardiac surgery. }\end{array}$ & $\begin{array}{l}\text { Composite of MACCE (ie, } \\
\text { death from any cause, stroke, } \\
\text { MI, or repeat } \\
\text { revascularization) }\end{array}$ & $\begin{array}{l}\text { The individual component of } \\
\text { the primary MACCE end } \\
\text { point, quality of life, and } \\
\text { cost-effectiveness. }\end{array}$ \\
\hline $\begin{array}{l}\text { Boudriot and } \\
\text { colleagues }^{14}\end{array}$ & $\begin{array}{l}\text { Patients aged } 18-80 \text { y with } \\
\text { stenosis }(>50 \%) \text { of the ULM } \\
\text { with or without additional } \\
\text { multivessel coronary artery } \\
\text { disease were included in this } \\
\text { multicenter study. Patients } \\
\text { had to be symptomatic or } \\
\text { have documented myocardial } \\
\text { ischemia. }\end{array}$ & $\begin{array}{l}\text { MI } 48 \mathrm{~h} \text { requiring immediate } \\
\text { intervention, additional } \\
\text { valvular heart disease } \\
\text { requiring surgery, previous } \\
\text { surgical treatment for } \\
\text { coronary artery or valvular } \\
\text { disease, severe peripheral } \\
\text { arterial disease, significant } \\
\text { carotid stenosis requiring } \\
\text { treatment, renal dysfunction } \\
\text { requiring dialysis, any } \\
\text { disease with limited life } \\
\text { expectancy, overt congestive } \\
\text { heart failure, and } \\
\text { contraindication to } \\
\text { antiplatelet therapy. } \\
\text { Angiographic exclusion } \\
\text { criteria were total occlusions, } \\
\text { extreme left-dominant } \\
\text { coronary artery perfusion, } \\
\text { and distal lesion length } \\
>30 \text { mm in a single lesion }\end{array}$ & $\begin{array}{l}\text { MACCE, which included death } \\
\text { from any cause, MI, and the } \\
\text { need for repeat } \\
\text { revascularization }\end{array}$ & $\begin{array}{l}\text { Each individual component of } \\
\text { the composite end point. }\end{array}$ \\
\hline $\begin{array}{l}\text { Erglis and } \\
\text { colleagues }^{16}\end{array}$ & $\begin{array}{l}\text { Eligible patients were those } \\
\text { with clinically symptomatic } \\
\text { LM disease with } \\
\text { angiographic evidence of } \\
>50 \% \text { diameter stenosis of } \\
\text { LM suitable for stent } \\
\text { implantation. All patients } \\
\text { were good candidates for } \\
\text { CABG. }\end{array}$ & $\begin{array}{l}\text { CABG to LAD artery branches } \\
\text { or LCX branches }\end{array}$ & $\begin{array}{l}\text { Neointimal growth (volume, } \\
\text { square, luminal diameter, and } \\
\text { late lumen loss) evaluated by } \\
\text { IVUS at } 6 \text { mo, or earlier if } \\
\text { clinically indicated. }\end{array}$ & $\begin{array}{l}\text { MACE were defined as death, } \\
\text { MI, and target lesion } \\
\text { revascularization }\end{array}$ \\
\hline
\end{tabular}


TABLE E1. Continued

\begin{tabular}{|c|c|c|c|c|}
\hline Trial & Main inclusion criteria & Main exclusion criteria & Primary end point & Secondary end point \\
\hline $\begin{array}{l}\text { ISAR-LEFT- } \\
\text { MAIN }\end{array}$ & $\begin{array}{l}\text { Patients aged }>18 \text { y with } \\
\text { ischemic symptoms or } \\
\text { evidence of myocardial } \\
\text { ischemia in the presence of } \\
>50 \% \text { de novo stenosis } \\
\text { located in the left main stem }\end{array}$ & $\begin{array}{l}\text { ST-segment elevation MI within } \\
48 \text { h of symptom onset; prior } \\
\text { bypass graft surgery; in-stent } \\
\text { restenosis; cardiogenic } \\
\text { shock; malignancies or other } \\
\text { comorbid conditions with life } \\
\text { expectancy }<1 \text { y or that might } \\
\text { result in protocol } \\
\text { noncompliance; left main } \\
\text { size }>4.5 \text { mm; planned staged } \\
\text { PCI procedure within } 30 \text { d } \\
\text { from index PCI; planned } \\
\text { elective surgical procedure } \\
\text { necessitating interruption of } \\
\text { clopidogrel during the first } \\
6 \text { mo after enrollment; known } \\
\text { allergy to the study } \\
\text { medications: clopidogrel, } \\
\text { rapamycin, paclitaxel, } \\
\text { stainless steel, or cobalt } \\
\text { alloy; pregnancy; or previous } \\
\text { enrollment in this trial }\end{array}$ & $\begin{array}{l}\text { The combined incidence of } \\
\text { death, MI, and target lesion } \\
\text { revascularization at } 1 \mathrm{y}\end{array}$ & $\begin{array}{l}\text { Angiographic restenosis on the } \\
\text { basis of the LMCA area } \\
\text { analysis at follow-up } \\
\text { angiography }\end{array}$ \\
\hline $\begin{array}{l}\text { ISAR-LEFT- } \\
\text { MAIN } 2\end{array}$ & $\begin{array}{l}\text { Patients aged }>18 \text { y with } \\
\text { ischemic symptoms or } \\
\text { evidence of myocardial } \\
\text { ischemia in the presence of } \\
>50 \% \text { de novo stenosis } \\
\text { located in the left main stem }\end{array}$ & $\begin{array}{l}\text { ST-segment elevation MI within } \\
<48 \text { h of symptom onset; } \\
\text { prior CABG surgery; in-stent } \\
\text { restenosis; cardiogenic } \\
\text { shock; malignancies or other } \\
\text { comorbid conditions with a } \\
\text { life expectancy <1 y; planned } \\
\text { staged PCI procedure within } \\
30 \text { d of index PCI; planned } \\
\text { elective surgical procedure } \\
\text { necessitating interruption of } \\
\text { P2Y12-receptor inhibitors } \\
\text { during the first } 6 \text { mo } \\
\text { postenrollment; known } \\
\text { allergy to the study } \\
\text { medications: everolimus, } \\
\text { zotarolimus, or cobalt alloy; } \\
\text { pregnancy; or previous } \\
\text { enrollment in this trial }\end{array}$ & $\begin{array}{l}\text { Combined incidence of death, } \\
\text { MI, and target lesion } \\
\text { revascularization }\end{array}$ & $\begin{array}{l}\text { Definite or probable stent } \\
\text { thrombosis at } 1 \mathrm{y} \text { and } \\
\text { angiographic restenosis } \\
\text { based on analysis of the left } \\
\text { main coronary artery area at } \\
\text { follow-up angiography }\end{array}$ \\
\hline
\end{tabular}

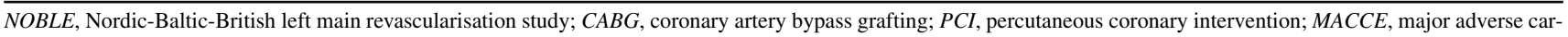
diac and cerebrovascular events; $M I$, myocardial infarction; EXCEL, Evaluation of XIENCE versus Coronary Artery Bypass Surgery for Effectiveness of Left Main Revascularization trial; SYNTAX, Synergy between Percutaneous Coronary Intervention with Taxus and Cardiac Surgery trial; MAE, major adverse event; LE MANS, Study of Unprotected Left Main Stenting Versus Bypass Surgery; ULMCA, unprotected left main coronary artery; euroSCORE, European System for Cardiac Operative Risk Evaluation; $L V E F$, left ventricular ejection fraction; TVF, target vessel failure; TVR, target vessel revascularization; PRECOMBAT, Premier of Randomized Comparison of Bypass Surgery versus Angioplasty Using Sirolimus-Eluting Stent in Patients with Left Main Coronary Artery Disease trial; $I V$, intravenous; $L M$, left main; $L A D$, left anterior descending; $L C X$, left circumflex; IVUS, intravascular ultrasound; MACE, major adverse cardiac event; ISAR-LEFT-MAIN, Intracoronary Stenting and Angiographic Results: Drug-Eluting Stents for Unprotected Coronary Left Main Lesions; $L M C A$, left main coronary artery. 


\section{NOBLE}

All-cause mortality: Death from any cause.

Cardiac death: Cardiac death was defined as any death due to a suspected cardiac cause (MI, low-output heart failure, fatal arrhythmia), unwitnessed death, and death of unknown cause. All procedure-related deaths, including those related to concomitant treatment, were classified as cardiac death. The end point was included post hoc. (Modified from Cutlip et al. Circulation. 2007;115:2344-51.) The information on cause of death was obtained from hospital patient files, general practitioners, or families if no other source was available.

Vascular death: Death caused by noncoronary vascular causes, including cerebrovascular disease, pulmonary embolism, ruptured aortic aneurysm, dissecting aneurysm, or other vascular diseases. The end point was included post hoc. (Modified from Cutlip et al. Circulation. 2007;115:2344-51.)

Nonprocedure-related MI: A increase in biochemical markers exceeding the decision limit for MI with at least 1 of the following; (1) ischemic symptoms, (2) ECG changes indicative of ischemia (ST-segment elevation or depression), and (3) development of a pathologic Q-wave with no relation to a PCI procedure.

Repeat revascularization: Any new PCI or CABG operation performed during follow-up. If an index revascularization was attempted or successful, any subsequent revascularization was counted as repeat revascularization. Attempted PCI was defined as an advancement of a wire in the coronary tree at least. Attempted CABG was defined as at least initiation of an index operation.

Procedure-related biomarker release: The diagnosis of a procedure-related biomarker increase required an increase in total CK or troponin-T/I. Because of the heterogeneity of biomarkers and various assays used during the study in participating centers, this comparison was omitted from the final analysis.

Procedural MI: Diagnosis of procedural MI for both PCI and CABG cases was based on CK-MB elevations when available. Patients needed to have stable angina pectoris as the clinical indication OR a normal baseline CK-MB, TnI, TnT, or highly sensitive TnT, to be assessable for procedural MI. Diagnosis required a CK-MB value $>10 \times$ URL or ULN to establish the diagnosis. The diagnosis could also be placed by the combination of a CKMB value above $5 \times$ URL or ULN, AND 1 or more of the following: (1) new pathologic Q waves in at least 2 contiguous leads or new persistent non-rate-related left bundle branch block or (2) angiographically documented graft or native coronary artery occlusion or new severe stenosis with thrombosis and/or diminished epicardial flow, or (3) imaging evidence of new loss of viable myocardium or new regional wall motion abnormality. The end point of procedural MI was included post hoc, and the definition was adapted to match the definition applied in the EXCEL trial on PCI versus CABG for LMCA stenosis. Periprocedural MI due to repeat revascularization during follow-up were assessed applying the 3rd Universal definition because CK-MB was not available in all event patients. A procedural MI according to this definition was counted as a nonindex procedural MI.

Nonprocedural myocardial infarction: Thygesen K, Alpert JS, Jaffe AS, et al. Third universal definition of myocardial infarction. Circulation. 2012;126:2020-35.

Target lesion revascularization: Repeat revascularization by PCI of any target segment treated during the index procedure. A target lesion segment was defined as a stented or balloon treated segment and its 5-mm margins.

LMCA revascularization: Any subsequent revascularization by PCI of the segments within $5 \mathrm{~mm}$ of any treated segment related to the LMCA or the LMCA bifurcation. Any revascularization by CABG of native LMCA including the LMCA bifurcation, or revascularization of a graft supplying the left anterior descending artery or circumflex arteries.

Definite stent thrombosis: Stent thromboses were categorized as acute, subacute, late, and very late and as definite, probable, and possible according to Academic Research Consortium criteria. (Cutlip et al. Circulation. 2007;115:2344-51.)

Symptomatic graft occlusion: Diagnosis of symptomatic graft occlusion required it to be detected during a clinically indicated coronary angiography. Stroke: Ischemic or hemorrhagic cerebrovascular event verified by brain CT or MRI.

Pulmonary embolus: The diagnosis of pulmonary embolus required verification by an appropriate CT scan.

EXCEL

Death: The cause of death will be adjudicated as being due to cardiovascular causes, noncardiovascular causes, or undetermined causes.

Cardiovascular death includes sudden cardiac death, death due to acute MI, heart failure or cardiogenic shock, stroke, other cardiovascular causes, or bleeding.

- Noncardiovascular death is defined as any death with known cause not of cardiac or vascular causes.

- Undetermined cause of death refers to a death not due to 1 of the above categories of cardiovascular death or to a noncardiovascular cause. For this trial, all deaths of undetermined cause will be included in the cardiovascular category

MI (protocol definition):

Postprocedure MI: Defined as the occurrence within $72 \mathrm{~h}$ after PCI or CABG of CK-MB $>10 \times$ URL*, OR

- $\mathrm{CK}-\mathrm{MB}>5 \times \mathrm{URL}^{*}$, PLUS

- New pathologic Q waves in at least 2 contiguous leads or new persistent nonrated-related LBBB, or

- Angiographically documented graft or native coronary artery occlusion or new severe stenosis with thrombosis and/or diminished epicardial flow, or

- Imaging evidence of new loss of viable myocardium or new regional wall motion abnormality

Spontaneous MI: Defined as the occurrence $>72 \mathrm{~h}$ after any PCI or CABG of:

The increase or decrease of cardiac biomarkers (CK-MB or troponin) $>1 \times$ URL* PLUS: 
- ECG changes indicative of new ischemia (ST-segment elevation or depression, in the absence of other causes of ST-segment changes such as left ventricular hypertrophy or bundle branch block), or

- Development of pathologic Q waves ( $\geq 0.04 \mathrm{sec}$ in duration and $\geq 1 \mathrm{~mm}$ in depth) in $\geq 2$ contiguous precordial leads or $\geq 2$ adjacent limb leads) of the ECG, or

- Angiographically documented graft or native coronary artery occlusion or new severe stenosis with thrombosis or diminished epicardial flow, or

- Imaging evidence of new loss of viable myocardium or new regional wall motion abnormality

Each MI will also be adjudicated as:

- ST-segment elevation MI

- Non-ST-segment elevation MI

- Each ST-segment elevation MI and non-ST-segment elevation MI will be subcategorized as

- Q-wave

- Non-Q-wave

- Unknown (no ECG or ECG not interpretable)

Stroke: The rapid onset of a new persistent neurologic deficit attributed to an obstruction in cerebral blood flow and/or cerebral hemorrhage with no apparent nonvascular cause (eg, trauma, tumor, or infection). A vascular neurologist or stroke specialist will determine whether a stroke has occurred and determine the stroke severity using the National Institutes of Health Stroke Scale Transient Ischemia Attack/Stroke questionnaire. Available neuroimaging studies will be considered to support the clinical impression and to determine if there is a demonstrable lesion compatible with an acute stroke. Strokes will be classified as ischemic, hemorrhagic, or unknown. Four criteria must be fulfilled to diagnosis stroke:

1. Rapid onset of a focal/global neurologic deficit with at least 1 of the following: change in level of consciousness, hemiplegia, hemiparesis, numbness or sensory loss affecting 1 side of the body, dysphasia/aphasia, hemianopia, amaurosis fugax, other new neurologic sign(s)/ symptom(s) consistent with stroke; and

2. Duration of a focal/global neurologic deficit $\geq 24 \mathrm{~h}$ or $<24 \mathrm{~h}$ if any of the following conditions exist:

i. At least 1 of the following therapeutic interventions:

a. Pharmacologic (ie, thrombolytic drug administration)

b. Nonpharmacologic (ie, neurointerventional procedure such as intracranial angioplasty)

ii. Available brain imaging clearly documents a new hemorrhage or infarct

iii. The neurologic deficit results in death

3. No other readily identifiable nonstroke cause for the clinical presentation (eg, brain tumor, trauma, infection, hypoglycemia, other metabolic abnormality, peripheral lesion, or drug side effect). Patients with nonfocal global encephalopathy will not be reported as a stroke without unequivocal evidence based upon neuroimaging studies.

4. Confirmation of the diagnosis by a neurology or neurosurgical specialist and at least 1 of the following:

a. Brain imaging procedure (at least 1 of the following):
i. CT scan
ii. MRI scan
iii. Cerebral vessel angiography

b. Lumbar puncture (ie, spinal fluid analysis diagnostic of intracranial hemorrhage)

All strokes with stroke disability of modified Rankin Scale $\geq 1$ (increase from baseline assessment) will be included in the primary end point. All diagnosed strokes (even with modified Rankin Scale 0) will also be tabulated.

Ischemia-driven revascularization:

A coronary revascularization procedure may be a CABG or PCI. The coronary segments revascularized will be subclassified as:

- Target Lesion: A lesion revascularized in the index procedure (or during a planned or provisional staged procedure). The LM target lesion extends from the left main stem ostium to the end of the 5-mm proximal segments of the left anterior descending and left circumflex arteries as well as the ramus intermedius if the latter vessel has a vessel diameter of $\geq 2 \mathrm{~mm}$.

- Target Vessel: The target vessel is defined as the entire major coronary vessel proximal and distal to the target lesion including upstream and downstream branches and the target lesion itself. The left main and any vessel originating from the left main coronary artery or its major branches is, by definition, considered a target vessel for the purposes of this trial (unless the LAD or LCX are occluded at baseline and no attempt was made to revascularize these territories by PCI or CABG).

- Target Vessel Nontarget Lesion: The target vessel nontarget lesion consists of a lesion in the epicardial vessel/branch/graft that contains the target lesion; however, this lesion is outside of the target lesion by at least $5 \mathrm{~mm}$ distal or proximal to the target lesion determined by quantitative coronary angiography.

- Nontarget Vessel: For the purposes of this trial, the only possible nontarget vessel would be the right coronary artery and its major branches that were not treated by PCI or CABG at the index procedure (unless the LAD or LCX are occluded at baseline and no attempt was made to revascularize these territories by $\mathrm{PCI}$ or $\mathrm{CABG})$. 


\section{TABLE E2. Continued}

All revascularization events will be adjudicated as ischemia driven or nonischemia driven. Revascularization will be considered ischemia driven if the diameter stenosis of the revascularized coronary segment is $\geq 50 \%$ by quantitative coronary angiography and any of the following criteria for ischemia are met:

- A positive functional study corresponding to the area served by the target lesion; or

- Ischemic ECG changes at rest in a distribution consistent with the target vessel; or

- Typical ischemic symptoms referable to the target lesion; or

- IVUS of the target lesion with a minimal lumen area of $\leq 4 \mathrm{~mm}^{2}$ for nonleft main lesions or $\leq 6 \mathrm{~mm}^{2}$ for left main lesions. If the lesions are de novo (ie, not restenotic), the plaque burden must also be $\geq 60 \%$; or

- Fractional flow reserve of the target lesion $\leq 0.80$

A target lesion revascularization for a diameter stenosis $<50 \%$ might be considered ischemia-driven by the Clinical Events Committee if there was a markedly positive functional study or ECG changes corresponding to the area served by the target lesion.

\section{Periprocedural major adverse events:}

The composite rate of any of the following, occurring within $30 \mathrm{~d}$ postprocedure

- Death

- Stroke

- MI

- Ischemia-driven revascularization

- TIMI major or minor bleeding

- Transfusion $\geq 2$ units of blood

- Major arrhythmia (supraventricular tachycardia requiring cardioversion, ventricular tachycardia or fibrillation requiring treatment, or bradyarrhythmia requiring temporary or permanent pacemaker)

- Any unplanned surgery or therapeutic radiologic procedure

- Renal failure (serum creatinine increase by $\geq 0.5 \mathrm{mg} / \mathrm{dL}$ from baseline or need for dialysis)

- Sternal wound dehiscence

- Infection requiring antibiotics

- Prolonged intubation $(>48 \mathrm{~h})$

- Postpericardiotomy syndrome

\section{LE MANS}

The major adverse events were defined as all-cause mortality, acute MI (defined as an increase in creatine phosphokinase-MB to $>3$ times the upper limit of normal after PCI and 5 times after CABG), repeat revascularization, acute heart failure (eg, pulmonary edema, cardiogenic shock), or low output syndrome requiring intravenous inotropic agents and/or intra-aortic balloon pump support, postprocedural complications leading to reintervention, stroke, arrhythmia (ventricular fibrillation, ventricular tachycardia, or atrial fibrillation), major bleeding requiring additional blood transfusion, and infections compromising postprocedural rehabilitation. Any cardiac mortality, acute MI, stroke, repeat intervention, and/or acute/ subacute in-stent thrombosis were considered MACCE.

Target vessel failure was defined as any MACCE related to insufficient flow through the LMCA, and TVR as any repeat intervention (PCI or CABG) caused by a narrowing of the LMCA. The incidence of stent thrombosis was evaluated in accordance with the Academic Research Consortium Definitions of Stent Thrombosis

\section{SYNTAX}

Deaths were considered cardiac unless an unequivocal, noncardiac cause was established.

Cerebrovascular accident was defined as a focal, central neurologic deficit lasting $>72 \mathrm{~h}$ that resulted in irreversible brain damage or body impairment.

Repeat revascularization was defined as any repeat PCI or CABG. Complete revascularization was defined as the successful treatment of all eligible lesions identified during the Heart Team conference and estimated postprocedure by the investigator.

MI was based on previous studies, MI was defined in relation to intervention status as follows i) after allocation but before treatment: Q -wave (new pathologic Q-waves in $\geq 2$ leads lasting $\geq 0.04 \mathrm{sec}$ with CK-MB levels elevated above normal), and non-Q-wave MI (elevation of CK levels $>2 \times$ the ULN with positive CK-MB or elevation of CK levels to $>2 \times$ ULN without new Q-waves if no baseline CK-MB was available); ii) $<7 \mathrm{~d}$ after intervention: new Q-waves and peak CK-MB/total CK $>10 \%$ or plasma level of CK-MB $5 \times \mathrm{ULN}$; iii) $7 \mathrm{~d}$ after intervention: new $\mathrm{Q}$ waves or peak CK-MB/total CK $>10 \%$ or plasma level of CK-MB $5 \times$ ULN or plasma level of CK $5 \times$ ULN. The CK/CK-MB enzyme levels were obtained and measured by a core laboratory for all randomized patients.

Per protocol graft occlusion and ST were considered acute if occurring $\leq 24 \mathrm{~h}$ after the study procedure, subacute if occurring $>24 \mathrm{~h}$ to $\leq 30 \mathrm{~d}$ after the study procedure, and late after $30 \mathrm{~d}$. Per protocol graft occlusion and stent thrombosis were defined as i) clinical presentation of an acute coronary syndrome with documentation of a flow limiting thrombus or occlusion within a bypass graft or adjacent to the anastomosis of a previously bypassed coronary artery (for CABG cases) or within or adjacent to a previously successfully treated artery (for PCI cases); ii) a Q-wave MI in the territory of $\geq 1$ treated vessels within first $30 \mathrm{~d}$. 
Boudriot and colleagues ${ }^{14}$

MI was defined as an increase in creatine kinase-MB activity $>3 \times$ the upper limit of normal after PCI and $>5 \times$ after $\mathrm{CABG}$. In addition, standard electrocardiographic criteria were applied.

The incidence of stent thrombosis was evaluated in accordance with the Academic Research Consortium definitions.

Repeat revascularization was defined as any revascularization by CABG or PCI within 12 mo and was subdivided into target lesion revascularization of the ULM and distally located lesions or those of the right coronary artery.

Erglis and colleagues ${ }^{16}$

MACE were defined as death, MI, and TLR. Patients with $>1$ event were assigned the highest rank event.

All deaths were considered to be of cardiac origin unless a noncardiac origin was diagnosed.

MI was diagnosed by elevation of myocardial damage biomarkers: 3-fold in troponin I and 5-fold in MB fraction of creatine kinase.

Target lesion revascularization was defined as a repeat intervention (surgical or percutaneous) to treat a luminal stenosis in the stent or within the 5-mm segments adjacent to the stent, including the ostium of the LAD or LCX artery.

\section{ISAR-LEFT-MAIN}

The diagnosis of MI required the presence of new significant Q waves on the electrocardiogram and/or elevation of CK-myocardial band isoform (or $\mathrm{CK}$ if the latter was not available) at least $2 \times$ the upper limit of normal in no fewer than 2 blood samples.

The TLR was defined as any repeat PCI involving the left main area or CABG involving at least 1 of the main left coronary vessels due to luminal renarrowing in the presence of symptoms or objective signs of ischemia.

Stent thrombosis was defined according to Academic Research Consortium criteria (Cutlip DE, Windecker S, Mehran R, et al. Clinical end points in coronary stent trials: a case for standardized definitions. Circulation. 2007;115:2344-51.).

Angiographic binary restenosis was defined as diameter stenosis $>50 \%$, measured by quantitative coronary angiography, in the left main area.

\section{ISAR-LEFT-MAIN 2}

The diagnosis of MI required the presence of new significant Q waves on electrocardiography or elevation of CK-MB isoform (or creatine kinase if the latter was not available) to at least 2 times the upper limit of normal in no fewer than 2 blood samples.

Target lesion revascularization was defined as any repeat PCI involving the left main area or CABG surgery involving at least 1 of the main left coronary vessels due to luminal renarrowing in the presence of symptoms or objective signs of ischemia.

Stent thrombosis was defined according to Academic Research Consortium criteria (Cutlip DE, Windecker S, Mehran R, et al. Clinical end points in coronary stent trials: a case for standardized definitions. Circulation. 2007;115:2344-51.).

Angiographic binary restenosis was defined as diameter stenosis $>50 \%$, measured by quantitative coronary angiography, in the left main area.

NOBLE, Nordic-Baltic-British left main revascularisation study; $M I$, myocardial infarction; $E C G$, electrocardiogram; $P C I$, percutaneous coronary intervention; $C A B G$, coronary artery bypass grafting; $C K$, creatine kinase; $C K-M B$, creatine-kinase MB form; Tn, troponin; $U R L$, upper reference limit; $U L N$, upper limit of normal; $E X C E L$, the Evaluation of XIENCE versus Coronary Artery Bypass Surgery for Effectiveness of Left Main Revascularization trial; $L B B B$, left bundle branch block; $L M C A$, left main coronary artery; $C T$, computed tomography; MRI, magnetic resonance imaging; EXCEL, Evaluation of XIENCE versus Coronary Artery Bypass Surgery for Effectiveness of Left Main Revascularization trial; $L M$, left main; $L A D$, left anterior descending; $L C X$, left circumflex; IVUS, intravascular ultrasound; TIMI, Thrombolysis in Myocardial Infarction; $L E$ MANS, Study of Unprotected Left Main Stenting Versus Bypass Surgery; MACCE, major adverse cardiac and cerebrovascular events; TVR, target vessel revascularization; SYNTAX, Synergy between Percutaneous Coronary Intervention with Taxus and Cardiac Surgery trial; TLR, target lesion revascularization; MACE, major adverse cardiac event; ISAR-LEFT-MAIN, Intracoronary Stenting and Angiographic Results: Drug-Eluting Stents for Unprotected Coronary Left Main Lesions. 
TABLE E3. Risk of bias of included randomized controlled trials

\section{NOBLE}

\begin{tabular}{lll}
\hline \multicolumn{1}{c}{ Risk of bias } & Authors' judgment & \multicolumn{1}{c}{ Support for judgment } \\
\hline Random sequence generation (selection bias) & Low risk & Computer-generated using permuted random blocks \\
\hline Allocation concealment (selection bias) & Low risk & Web-based computer randomization \\
\hline Blinding of participants and personnel (performance bias) & High risk & Blinding not applicable \\
\hline Blinding of outcome assessment (detection bias) & Low risk & Outcome assessors blinded \\
\hline Incomplete outcome data (attrition bias) & Unclear risk & $>20 \%$ losses (31\% losses to follow-up) \\
\hline Selective reporting (reporting bias) & Low risk & All expected outcomes included \\
\hline Other bias & Unclear risk & Primary end point timing changed \\
\hline \multicolumn{1}{c}{ Risk of bias } & EXCEL & \\
\hline & Authors' judgment & \\
\hline Random sequence generation (selection bias) & Low risk & Variable block random allocation \\
\hline Allocation concealment (selection bias) & Low risk & Interactive voice-based or Web-based system \\
\hline Blinding of participants and personnel (performance bias) & High risk & Blinding not applicable \\
\hline Blinding of outcome assessment (detection bias) & Low risk & Outcome assessors blinded \\
\hline Incomplete outcome data (attrition bias) & Low risk & $8 \%$ of participants were lost to follow-up; reasons reported \\
\hline Selective reporting (reporting bias) & Low risk & Study protocol is available, all expected outcomes included \\
\hline Other bias & Low risk & Free of other sources of bias \\
\hline
\end{tabular}

LE MANS

\begin{tabular}{|c|c|c|}
\hline Risk of bias & Authors' judgment & Support for judgment \\
\hline Random sequence generation (selection bias) & Unclear risk & Randomization stated to have been done but no method reported \\
\hline Allocation concealment (selection bias) & Unclear risk & Not specified \\
\hline Blinding of participants and personnel (performance bias) & High risk & Blinding not applicable \\
\hline Blinding of outcome assessment (detection bias) & Low risk & Blinded outcome assessors \\
\hline Incomplete outcome data (attrition bias) & Low risk & $11.4 \%$ of participants were lost to follow-up; reasons reported \\
\hline Selective reporting (reporting bias) & Low risk & Include all expected outcomes \\
\hline Other bias & Low risk & Free of other sources of bias \\
\hline \multicolumn{3}{|c|}{ PRECOMBAT } \\
\hline Risk of bias & Authors' judgment & Support for judgment \\
\hline Random sequence generation (selection bias) & Low risk & Computer-generated random allocation sequence \\
\hline Allocation concealment (selection bias) & Low risk & Sealed envelopes concealed the allocation \\
\hline Blinding of participants and personnel (performance bias) & High risk & Blinding not applicable \\
\hline Blinding of outcome assessment (detection bias) & Low risk & Outcome assessors blinded \\
\hline Incomplete outcome data (attrition bias) & Low risk & $6.8 \%$ of participants were lost to follow-up; reasons reported \\
\hline Selective reporting (reporting bias) & Low risk & Study protocol is available, all Expected outcomes included \\
\hline Other bias & Low risk & Free of other sources of bias \\
\hline \multicolumn{3}{|c|}{ SYNTAX } \\
\hline Risk of bias & Authors' judgment & Support for judgment \\
\hline Random sequence generation (selection bias) & Low risk & Variable block random allocation \\
\hline Allocation concealment (selection bias) & Low risk & Central allocation (Interactive Voice Response System) \\
\hline Blinding of participants and personnel (performance bias) & High risk & Blinding not applicable \\
\hline Blinding of outcome assessment (detection bias) & Low risk & Outcome assessors blinded \\
\hline Incomplete outcome data (attrition bias) & Low risk & $5.2 \%$ of participants were lost to follow-up; reasons reported \\
\hline Selective reporting (reporting bias) & Low risk & Study protocol is available, all expected outcomes included \\
\hline Other bias & Low risk & Free of other sources of bias \\
\hline
\end{tabular}


TABLE E3. Continued

\begin{tabular}{lll}
\hline \multicolumn{1}{c}{ Risk of bias } & Boudriot and colleagues $^{14}$ & \multicolumn{1}{c}{ Support for judgment } \\
\hline Random sequence generation (selection bias) & \multicolumn{2}{c}{ Authors' judgment } \\
\hline Allocation concealment (selection bias) & Low risk & Computerized randomization program \\
Blinding of participants and personnel (performance bias) & Unclear risk & Concealment of allocation was not reported \\
Blinding of outcome assessment (detection bias) & High risk & Blinding not applicable \\
Incomplete outcome data (attrition bias) & Low risk & Blinded outcome assessors \\
Selective reporting (reporting bias) & Low risk & $0.5 \%$ of participants were lost to follow-up \\
\hline Other bias & Low risk & All expected outcomes included \\
\hline
\end{tabular}

\begin{tabular}{lll}
\hline \multicolumn{1}{c}{ Risk of bias } & Erglis and colleagues & \\
\hline Random sequence generation (selection bias) & & \\
\hline Allocation concealment (selection bias) & Unclear & No sufficient information to allow judgment \\
Blinding of participants and personnel (performance bias) & Unclear & No sufficient information to allow judgment \\
Blinding of outcome assessment (detection bias) & Unclear & No sufficient information to allow judgment \\
Incomplete outcome data (attrition bias) & Unclear & No sufficient information to allow judgment \\
Selective reporting (reporting bias) & Low risk & No patient lost to follow-up \\
Other bias & Unclear & No sufficient information to allow judgment \\
\hline
\end{tabular}

\begin{tabular}{lll}
\hline \multicolumn{1}{c}{ Risk of bias } & ISAR-LEFT-MAIN \\
\hline Random sequence generation (selection bias) & Low risk & Computer-generated sequence \\
\hline $\begin{array}{l}\text { Allocation concealment (selection bias) } \\
\text { Blinding of participants and personnel (performance bias) }\end{array}$ & $\begin{array}{l}\text { High risk } \\
\text { Blinding of outcome assessment (detection bias) }\end{array}$ & $\begin{array}{l}\text { Sealed opaque envelopes } \\
\text { The article does not report information about the blinding } \\
\text { of participants and personnel. We assume this is an } \\
\text { open-label study }\end{array}$ \\
\hline Incomplete outcome data (attrition bias) & Low risk & $\begin{array}{c}\text { An events committee blinded to treatment allocation } \\
\text { adjudicated all adverse clinical events. }\end{array}$ \\
\hline $\begin{array}{l}\text { Selective reporting (reporting bias) } \\
\text { Other bias }\end{array}$ & Low risk & $\begin{array}{l}\text { No patient lost to follow-up } \\
\text { No sufficient information to allow judgment }\end{array}$ \\
\hline
\end{tabular}

\begin{tabular}{|c|c|c|}
\hline \multicolumn{3}{|c|}{ ISAR-LEFT-MAIN 2} \\
\hline Risk of bias & & \\
\hline Random sequence generation (selection bias) & Low risk & $\begin{array}{l}\text { Randomization was done by a web-based computer } \\
\text { randomization system }\end{array}$ \\
\hline Allocation concealment (selection bias) & Low risk & $\begin{array}{l}\text { Patients were assigned to the allocated treatment according to } \\
\text { Randomization by the local research team }\end{array}$ \\
\hline Blinding of participants and personnel (performance bias) & High- risk & Open-label study \\
\hline Blinding of outcome assessment (detection bias) & High risk & Open-label study \\
\hline Incomplete outcome data (attrition bias) & High risk & 17 patients lost to follow-up, unlikely to have influenced results \\
\hline Selective reporting (reporting bias) & Unclear & No sufficient information to allow judgment \\
\hline Other bias & Low risk & $\begin{array}{l}\text { Aarhus University Hospital was the main sponsor of the trial. } \\
\text { Biosensors provided an institutional research grant for the trial } \\
\text { but had no role in the study design; in the collection, analysis, } \\
\text { and interpretation of the data; in the writing of this report; or in } \\
\text { the decision to submit the paper for publication. }\end{array}$ \\
\hline
\end{tabular}


BMS $1.042(-0.5564,3.093)$

\section{$-0.3287(-0.9366,0.2736)$}

$1.166(-0.5108,3.262) \quad$ BMS

$0.1185(-0.3578,0.6011) \quad-1.042(-3.093,0.5564) \quad$ CABG

$1.348(-0.2925,3.43)$

$0.833(-0.7845,2.895)$

$0.843(-0.8156,2.939)$

$-0.1858(-0.7829,0.4146)-1.348(-3.43,0.2925) \quad-0.3038(-0.6653,0.05129)$ EES

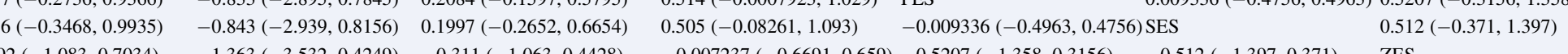

$-0.192(-1.083,0.7034)$

\begin{tabular}{|c|c|}
\hline \multirow[t]{7}{*}{ MI } & Bio-ES \\
\hline & $0.7653(-0.5427,2.094)$ \\
\hline & $1.087(0.3979,1.864)$ \\
\hline & $1.148(0.3826,1.983)$ \\
\hline & $0.7197(-0.1613,1.647)$ \\
\hline & $0.8682(-0.1073,1.881)$ \\
\hline & $0.2824(-1.26,1.7)$ \\
\hline
\end{tabular}

SES

$-0.007237(-0.6691,0.659)-0.5207(-1.358,0.3156) \quad-0.512(-1.397,0.371) \quad$ ZES

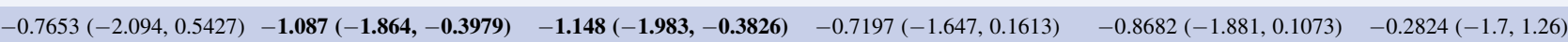

BMS

$\begin{array}{lll}-1.087(-1.864,-0.3979) & -\mathbf{1 . 1 4 8}(-\mathbf{1 . 9 8 3 ,}-\mathbf{0 . 3 8 2 6}) & -0.7197(-1.647,0.1613) \\ -0.3304(-1.433,0.7578) & -0.3903(-1.537,0.7464) & 0.04066(-0.9842,1.073)\end{array}$

$-0.107(-1.285,1.074) \quad 0.4879(-1.154,2.221)$

$0.3304(-0.7578,1.433) \quad$ CABG $\quad-0.05837(-0.3818,0.264) \quad 0.3709(-0.1532,0.9082)$

$0.3903(-0.7464,1.537) \quad 0.05837(-0.264,0.3818) \quad$ EES

$0.4306(-0.1877,1.057)$

$.2247(-0.4473,0.9072) \quad 0.8076(-0.3876,2.188)$

$0.2832(-0.4617,1.04) \quad 0.8652(-0.2814,2.211)$

$-0.1469(-0.7678,0.4729) \quad 0.4399(-0.8755,1.905)$

$\begin{array}{lll} & \\ 0\end{array}$

$\begin{array}{lllll} & -0.2247(-0.9072,0.4473) & -0.2832(-1.04,0.4617) & 0.1469(-0.4729,0.7678) & \text { SES }\end{array}$

Revascularization Bio-ES $-0.4879(-2.221,1.154)$

$-0.5882(-2.112,0.7967) \quad$ ZES

$-0.9567(-2.033,-0.01152)$ BM

$-0.8076(-2.188,0.3876)$

$-0.4399(-1.905,0.8755)$

$5882(-0.7967,2.112)$

\section{$0.641(0.293,1.003)$}

$1.596(0.7295,2.623)$

$-1.596(-2.623,-0.7295)$

$-0.0982(-0.5659,0.3653)$

$0.0982(-0.3653,0.5659) \quad 1.054(0.1309,2.118) \quad-\mathbf{0 . 5 4 3 2}(-\mathbf{0 . 8 4 9 7},-\mathbf{0 . 2 4 5 5})$ EES

$0.1277(-0.3418,0.6017) \quad 1.082(0.1973,2.116)$

$054(-2.118,-0.1309)$

$-0.1277(-0.6017,0.3418) \quad 0.0608(-0.4646,0.59)$

$0.1264(-0.5473,0.8067)$

$-0.0608(-0.59,0.4646) \quad 0.8956(-0.04512,1.975)$

- $.514(-\mathbf{0 . 8 2 7 2},-\mathbf{0 . 2 0 7 2}) 0.02982(-0.4039,0.4618) \quad$ PES

$.082(-2.116,-0.1973)$

$-0.8956(-1.975,0.045$

$-0.832(-1.994,0.224)$

$-0.1264(-0.8067,0.5473) \quad 0.832(-0.224,1.994)$

$\begin{array}{lll} & -0.1886(-0.6081,0.225)\end{array}$

Stroke Bio-ES

$1.752(-1.362,5.447)$

$-0.8569(-2.321,0.5531)$

$-1.115(-3.055,0.7876)$

$-1.63(-3.525,0.2809)$

$-0.06595(-0.7658,0.6265)$ ZES

$0.8569(-0.5531,2.321) \quad-0.8718(-4.328,1.88) \quad$ CAB

$1.115(-0.7876,3.055)$

$0.6285(-2.407,4.272)$

$\begin{array}{ll}-0.8718(-4.328,1.88) & \text { CABG } \\ -0.6285(-4.272,2.407) & 0.2518(-1.021,1.538)\end{array}$

$1.63(-0.2809,3.525)$

$-0.1115(-3.776,2.902) \quad 0.7692(-0.5028,2.008)$

$-0.2518(-1.538,1.021)$

$0.1115(-2.902,3.776)$

$0.06921(-2.946,3.726)$

$0.7689(0.1983,1.353)$

$1.673(-0.2075,3.549)$

$0.06921(-3.726,2.946) 0.805(-0.4157,2.035)$

EES

$-0.7692(-2.008,0.5028)$

$-0.805(-2.035,0.4157)$

$2256(-0.2644,0.7221)$

$0.6292(-2.364,3.531)$

Death/MI/Stroke Bio-ES

\section{$-1.157(-5.375,2.635) \quad-0.2288(-2.902,2.285)$}

$.5174(-1.308,2.266) \quad \mathrm{P}$

PES

$-0.5585(-2.292,1.229)$

$-0.04(-1.415,1.31)$

0.5585(-1.229,2.292) $0.04(-1.31,1.415) \quad$ SES

$0.4615(-0.3563,1.319)$

$-0.9973(-3.913,1.835)$

$-1.037(-3.959,1.765) \quad$ ZES

$-0.5147(-0.8634,-0.1697)$

$-0.6938(-1.086,-0.3051)$

$\mathbf{- 0 . 7 1 5 8}(-\mathbf{1 . 1 7},-\mathbf{0 . 2 6 3 4}) \quad-0.2929(-0.9653,0.3897)$

$0.5147(0.1697,0.8634)$

$0.4848(-0.3656,1.374) \quad 0.3071(-0.5049,1.154)$

$-0.4848(-1.374,0.3656)-0.02384(-0.2622,0.2147)$ EES

$\begin{array}{llll}-0.3071(-1.154,0.5049) & 0.1551(-0.1429,0.4557) & 0.1792(-0.2039,0.5603)\end{array}$

$0.7158(0.2634,1.17)$

$-0.1792(-0.5603,0.2039)$

$-0.1771(-0.5554,0.199) \quad 0.2453(-0.3767,0.8807)$

$0.02207(-0.3617,0.4051) \quad$ SES $0.02207(-0.4051,0.3617) 0.401(-0.2901,1.101)$

$-0.7091(-1.772,0.3203)-0.2453(-0.8807,0.3767)-0.2222(-0.8121,0.3544)-0.401(-1.101,0.2901)$

$0.4237(-0.3051,1.162)$

Bio-ES, Biolimus-eluting stent; $B M S$, bare metal stent; $C A B G$, coronary artery bypass grafting; $E E S$, everolimus-eluting stent; $P E S$, paclitaxel-eluting stent; $S E S$, sirolimus-eluting stent; $Z E S$, zotarolimus-eluting stent; $M I$, myocardial infarction. 